NBER WORKING PAPER SERIES

\title{
LEAVING MONEY ON THE TABLE? SUBOPTIMAL ENROLLMENT IN THE NEW SOCIAL PENSION PROGRAM IN CHINA
}

\author{
Xi Chen \\ Lipeng $\mathrm{Hu}$ \\ Jody L. Sindelar \\ Working Paper 24065 \\ http://www.nber.org/papers/w24065 \\ NATIONAL BUREAU OF ECONOMIC RESEARCH \\ 1050 Massachusetts Avenue \\ Cambridge, MA 02138 \\ November 2017
}

\begin{abstract}
We are grateful to have access to the data from the China Family Panel Studies (CFPS), which is funded by 985 Program of Peking University and carried out by the Institute of Social Science Survey of Peking University. Financial support from the James Tobin Research Fund at Yale Economics Department, the U.S. PEPPER Center Career Development Award (P30AG021342), and an NIH/NIA grant (R03 AG048920) are acknowledged. We acknowledge comments from participants at the following conferences and seminars: Center for Retirement Research at Boston College, AEA annual meetings, India Statistical Institute (ISI), IZA Labor Economics Conference, UPenn, University of Minnesota, New York Academy of Medicine, Gerontological Association of America (GSA), National University of Singapore, and Yale University. The views expressed herein and any remaining errors are those of the authors and do not represent any official agency. The views expressed herein are those of the authors and do not necessarily reflect the views of the National Bureau of Economic Research.
\end{abstract}

NBER working papers are circulated for discussion and comment purposes. They have not been peer-reviewed or been subject to the review by the NBER Board of Directors that accompanies official NBER publications.

(C) 2017 by Xi Chen, Lipeng Hu, and Jody L. Sindelar. All rights reserved. Short sections of text, not to exceed two paragraphs, may be quoted without explicit permission provided that full credit, including $\odot$ notice, is given to the source. 
Leaving Money on the Table? Suboptimal Enrollment in the New Social Pension Program

in China

$\mathrm{Xi}$ Chen, Lipeng $\mathrm{Hu}$, and Jody L. Sindelar

NBER Working Paper No. 24065

November 2017

JEL No. D13,D14,D15,H55,I3

\section{ABSTRACT}

China's recently implemented New Rural Pension Scheme (NRPS), the largest social pension program in the world, was designed to provide financial protection for its rural population and reduce economic inequities. Yet the impact of this program is mitigated if those eligible fail to enroll. This paper examines the extent to which pension-eligible individuals, and their families, make optimal pension decisions. Families are involved in the NRPS decisions because, in most cases, adult children need to enroll as a prerequisite of their parents' receipt of benefits. We examine the decisions of both those eligible for pension benefits (i.e. over 60 years old) and their adult children. We use the rural sample of the 2012 China Family Panel Study to study determinants of the decision to enroll in NRPS, premiums paid, and time taken to enroll. We find evidence of low and suboptimal pension enrollment by eligible individuals and their families. Suboptimal enrollment takes various forms including failure to switch from the dominated default pension program to NRPS and little evidence that families make mutually beneficial intra-family decisions. For the older cohort, few individual and family characteristics are significant in enrollment decisions, but village characteristics play an important role. For the younger cohort, we find that more individual-level characteristics are significant, including own and children's education. Village characteristics are important but not as much as for the older cohort.

$\mathrm{Xi}$ Chen

Yale University, School of Public Health

Department of Health Policy \& Management Department of Economics

60 College Street, P.O. Box 208034

New Haven, CT 06520-8034

xi.chen@yale.edu

Lipeng $\mathrm{Hu}$

National School of Development

Peking University

Beijing 100871

China

lipenghu@gmail.com
Jody L. Sindelar

Yale School of Public Health

Yale University School of Medicine

60 College Street, P.O. Box 208034

New Haven, CT 06520-8034

and NBER

jody.sindelar@yale.edu 


\section{Introduction}

In 2009, China introduced to its rural population the world's largest social pension, the New Rural Pension Scheme (NRPS). This covered population tends to be of lower education and to have lower income and worse health than its urban counterpart. The NRPS was designed to provide the rural elderly, especially those with low income, with basic protection against poverty in old age. The NRPS was also introduced in part due to erosion of the traditional system of intergenerational cohabitation, in which children would provide in-person care for elderly family members and share incomes. The lower rates of cohabitation with children are due to both the large outmigration of younger generations and the persistent decline in the fertility rate. Consequently, the elderly currently need more market-based services to substitute for the lack of in-person family care. The increased life expectancy in China leaves the elderly living alone for more years. ${ }^{2}$ Thus, many rural elderly are increasingly likely to suffer from too little support without the rural pension system. However, without a high uptake of NRPS, protection will remain low.

The NRPS was also launched to replace the failed, unsubsidized rural pension program initiated in the 1990s, i.e. the Old Rural Pension Scheme (ORPS). In contrast to ORPS, both the central and local governments generously subsidize the NRPS. The subsidy is particularly robust for those in the special phase-in period at program initiation, allowing elderly persons at the time of local rollout to receive benefits despite never having paid into the system. This special phase-in period provides an important opportunity to study enrollment decisions.

We use the 2012 China Family Panel Study (CFPS) to explore determinants of the decision to enroll in NRPS, premiums paid, and time to enrollment. This paper empirically investigates the extent to which people are responding to the new pension program with optimal financial decisions. To the extent that they do not respond optimally, we also examine who fails to enroll, and why. Specifically, we examine the economic incentives to enroll and factors that could directly and indirectly affect enrollment decisions. The rollout of the program to all counties in China prior to the 2012 survey provides us with the opportunity to observe our three outcome variables the: decision to enroll, timing of enrollment, and size of individual premium contribution. We examine these decisions both for those eligible for a pension and their adult children. We focus on the latter due to the requirement that children need to enroll to make their elderly parents eligible for NRPS, and because they may also have their own motivations to enroll for their futures.

The Family Binding Policy in China requires at least one child (aged 16 years or above, not enrolled in school, and holding rural registration) to enroll in the NRPS to make their elderly parents eligible for pension benefits. Note that a large proportion of elderly parents have multiple children due to the loosely implemented One Child Policy in rural China. The enrolling adult child must pay premiums each year for his or her parents to receive pension payments. We examine separately the incentives and decisions of those over and under the age of 60 , due to this important policy and other

\footnotetext{
${ }^{2}$ By 2050, 32.8 percent of China's population will be above age 60, which will be the largest in size in the world (United Nations 2013).
} 
differences in coverage and contribution requirements by age. Specifically, we separately examine individuals over age 60 who have children, and also those between the ages of 45 and 60 . We ignore those under 45 as they have little incentive to enroll until later in life, even with the binding policy. People older than age 60 have straightforward incentives to enroll in NPRS as it is noncontributory for this initial cohort of the elderly. The decisions of people aged 45-60 are more complicated, for several reasons. Importantly, their decision to enroll may be affected by the desire to ensure benefits for their parents. If they choose to enroll, they also must decide when to enroll, and at what level of premiums.

We find that only half of the small percentage of childless seniors who could benefit immediately without being subject to the Family Binding Policy enroll. Children and their elderly parents could make simple arrangements to enroll, and have immediate pension benefits to both generations, but many fail to do so, thus leaving money 'on the table'. Moreover, a sizable portion of respondents could obtain higher benefits simply by switching from the unsubsidized ORPS (the default program) to the highly subsidized NRPS, but again fail to do so. Surprisingly, although the poorest households (in the bottom quintile) are more likely to enroll as compared to their richer counterparts, those in the next lowest quintiles are not more likely to enroll. And none of the lowest quintiles enroll more rapidly despite presumably having more to gain in terms of improvement in their well-being.

Our empirical investigation has several notable strengths. First, we contribute to the literature by making the first attempt to examine suboptimal pension enrollment and exploring plausible explanations to the puzzle of low pension enrollment and, more generally, inadequate planning for old age ${ }^{3}$. Second, we contribute to the literature by examining intra-family and intergenerational arrangements as they are key to optimal pension decisions. Our ability to link older parents and children (even those who have migrated) enables us to observe intra-family dynamics. Third, because the 2012 CFPS survey was fielded on average two years after the implementation of NRPS, we are able to compare the actual enrollment to some clear-cut gains to enrollment that occurred in the initial rollout. In this post-enrollment period, respondents would have had ample time to make decisions. Further, we collect and match county administrative data on pension roll-out with individual's pension choices to obtain precisely measured pension enrollment decisions.

Another contribution of this paper is that while most of the literature on pension decisions relates to the developed world, this paper examines pension decisions in a middle-income country. As the country with the world's largest population and pension system, China's experience demands analysis. In addition, the program is growing

\footnotetext{
${ }^{3}$ For example, people often fail to plan adequately for retirement. A sizable fraction of those close to retirement age do not plan for retirement (Lusardi 1999) or make adjustments to consumption and saving (Hubbard et al. 2005); this holds even among respondents with high educational attainment (Ameriks et al. 2003). Employees fail to enroll in a timely manner and fail to obtain the maximum payouts (Campbell 2006; Chalmers et al. 2014). Also, people are uninformed about the characteristics of their pension plans (Mitchell 1988; Gustman and Steinmeier 2001), respond to the complexity inherent in retirement plan choices by simply choosing the default option (Madrian and Shea 2001; Clark et al. 2015), and leave "\$100 bills on the sidewalk" by declining matching retirement contributions that can be immediately withdrawn (Choi et al. 2011).
} 
dramatically as China is currently integrating rural and urban social pensions. Once completed, this unified pension system may serve more than 800 million residents, doubling the current size of the NRPS (Chen 2016). Thus, lessons learned from analysis of the NPRS have an immediate application.

The rest of the paper is organized as follows. Section 2 provides institutional background on the New Rural Pension Scheme. Section 3 discusses the conceptual framework, provides predictions about optimal enrollment decisions, and explains the empirical methods. Section 4 introduces the dataset and the analytical sample. Section 5 discusses the empirical results. Section 6 concludes and discusses potential explanations and policy implications.

\section{Institutional Background: The New Rural Pension Scheme in China}

Despite rapid overall economic growth in China, income growth in rural areas has not matched that of urban areas. NRPS was launched to help address this geographical inequity and to protect rural populations against poverty in old age. Officially launched in September 2009, after a few years of piloting in selected areas of the country, the NRPS was to replace ORPS, an older and unsuccessful rural pension program implemented in the 1990s. Since 2009, ORPS has remained in operation but not accepted new enrollees. The two programs are mutually exclusive in enrollment but existing ORPS clients can simply transfer their contributed premiums to the NRPS. In contrast to ORPS, NRPS is subsidized at both provincial and national levels. By 2012, the NRPS had been introduced into all counties of China, thus making more than 400 million eligible for enrollment and providing the potential for nationwide, subsidized old-age support to rural China's elderly population (see Appendix Figure 1). Yet, about 17 percent of those over age 45 (i.e. 12 percent of those aged 45-60 and 24 percent of those over 60) have not switched from ORPS to NRPS, though NRPS clearly dominates ORPS (Table 1 and Appendix Figure 2). ${ }^{4}$

All residents with rural registration (Hukou), aged 16 or above and not in school, can voluntarily enroll in NRPS. No cumulative work histories are required ${ }^{5}$. Individuals aged 16-60 at the time of the rollout can establish and contribute to private accounts at varying levels. Such private accounts are funded by and eventually paid to the individual and can be inherited at death. However, those of 60 or over at the time of the local rollout did not have the opportunity to establish private accounts.

Those over age 60 at the time of the rollout were not required to have contributed to the pension system to be eligible for basic pension benefits. However, the Family Binding Policy stipulates that they are eligible for basic pension benefits only if at least one of their adult children eligible for the NRPS also enrolls. If there is no such adult child, the parent is eligible for benefits by default. People aged between 45 and 60 can contribute for any time period before age 60 to be eligible for pension benefits. ${ }^{6}$ For

\footnotetext{
${ }^{4}$ Note that even if all were to switch to NRPS, 30 percent of the younger cohort and 20 percent of the older cohort would not have enrolled in NRPS.

5 The lack of a contribution requirement perhaps occurs in part because most rural residents work in the informal sector, with no formal documentation of work contribution.

${ }^{6}$ In order to support the financial stability of NPRS, the government recommends that those aged 4560 contribute as much as possible to NRPS, although there is no financial incentive for them to do so.
} 
individuals aged 16-44 at rollout, contributions must have been made into the system for at least 15 years before benefits can be received at age 60 .

The lowest level of pension premium paid by an individual is $100 \mathrm{CNY}$ per year per person, but wealthier provinces often set higher premium levels, and consequently the premiums paid vary greatly by province. Funding comes in part from the required local government subsidies of $30 \mathrm{CNY}$ per person per year for the first $100 \mathrm{CNY}$ of premiums contributed to the individual account; there is a lower than proportional subsidy for additional premiums contributed. In addition, to compensate for the lower fiscal capacity of local governments in central and western China, the national government finances all basic pension benefits in these regions, compared with only 50 percent of the basic pension benefits in eastern China.

Upon reaching age 60, eligible individuals can receive payments from their government provided account. This basic pension benefit ranges from 55 to $380 \mathrm{CNY}$ per month per person in 2012 (Cai et al. 2012; Cheng et al. 2017); the variation is due to adjustments for the cost of living at the province level (Chen, Eggleston, Sun 2016). They can also receive payments from their private account if they established one. Benefits are paid regardless of working status. Because pension benefits are distributed directly to an individual's bank accounts without a need to claim benefits in person, migration may not discourage enrollment. In rural China, almost all older persons have at least one bank account.

\section{Conceptual Framework and Empirical Approach}

\subsection{Conceptual Framework}

NRPS enrollment decisions depend on the expected benefits and costs of the NRPS, which in turn depend on a variety of factors. A key aspect is how generations within each family are linked in enrollment decisions. The generations are naturally linked since in Chinese culture, intergenerational ties are strong, ranging from cohabitation, to older parents providing childcare to their grandchildren, to the role of sons in taking responsibility for their elderly parents. In addition, the rules of NRPS, as discussed above, require that at least one child enrolls to make the older parents eligible for NRPS, unless the parents are childless. These considerations link the enrollment decisions of both generations not only to their own characteristics but also to those of the other generation. Given the out-migration of children, village characteristics may also affect the decisions of the older parents left behind, because their children are no longer around to give help.

Below we discuss these and other factors and their potential impact on enrollment decisions. Because both the set of factors relevant to the decisions and their hypothesized impacts will differ somewhat across the two generations, we discuss them separately below but also focus on the commonalities and particularly on the intergenerational linkages.

Individuals over age 60 are the most likely to enroll in NRPS as the program is designed to benefit them. Their benefits to enrollment are greater if they are younger (but at least 60 years old) or if their spouses are also eligible. A pension-eligible spouse 
may promote enrollment via mutual assistance and income and information sharing between the couple. There may also be gender differences that need to be determined empirically. The childless over the age of 60 at the time of roll-out have the most clearcut incentive to enroll: they are immediately eligible for pension payouts but are not required to contribute and are not subject to the Family Binding Policy.

For those with children, at least one child must enroll and contribute financially to NRPS. When altruism alone is not enough to encourage enrollment by the adult children, then intra-family or intergenerational agreements might facilitate enrollment. Such agreements could be implicit or explicit, and payments might be non-financial (older parents providing childcare or housing) or financial (giving money to pay for the child's NRPS contribution). The costs and benefits of these arrangements for both generations would depend on the ages, number, and gender of both the older parents and their children.

Adult children can play a central, but mixed, role in parents' enrollment decisions for multiple reasons. First, the greater the number of children, the greater the likelihood of at least one child enrolling or more children collectively paying pension premiums for their parents' benefits. However, a larger number of children may also reflect stronger informal old-age support that may offset motives for pension enrollment (Packard et al. 2002; Li and Olivera 2005; Auerbach et al. 2007; Ebenstein and Leung 2010). Second, the older the adult children are, the greater the expected, discounted benefit to them of enrolling, and again, the more willing they might be to enroll ${ }^{7}$. Third, children's out-migration likely weakens emotional and geographical ties to their parents and the ability to make intra-family commitments to enroll parents with the Family Binding Policy. Fourth, the better the decision-making abilities of elders and their children (e.g. higher educational attainment), the greater the probability of a parent understanding the benefits of enrolling. Children may play a large role, as their education is on average higher than that of their parents.

Financial protection available to older parents could have offsetting impacts on enrollment decisions. Stronger financial protection, such as from their children, spouses, other pension and non-pension income, and health insurance coverage, ${ }^{8}$ may financially enable older persons to enroll, and enroll more rapidly. However, such protection may also reduce the need to enroll. Clearly, poor health could increase the demand for both pension income and personal care services, but poor health might also reduce the number of years over which to expect to reap the returns from NPRS. These are potentially offsetting impacts that must be determined empirically.

For the elderly, there is only the potential for financial gain, and no risk of losing money, so trust in government should play little role in enrollment decisions; although

\footnotetext{
7 Yet adult children might resist contributing due to: distrust of the government continuing the program, and of payout levels; skepticism that the parent would redistribute the payouts; lack of financial resources; lack of altruism; and other factors.

${ }^{8}$ Health insurance coverage could serve either as a substitute for or complement to NRPS. It would be a substitute as it could help with both the financial risk and provision of care. It would be a complement for at least three reasons: 1) both serve as a risk reduction approach; 2) health insurance coverage may raise one's life expectancy and expectancy of accruing greater pension benefits (Lei and Lin 2009; Wagstaff et al. 2009; Kimberly et al. 2010; Hu et al. 2012); and 3) both may be due to greater trust in government (Li and Olivera 2005).
} 
there might be some residual impact. For example, parents might altruistically be concerned about the long-term viability of a system that might put their children's funds at risk (Crabbe 2005; Lei et al. 2013), and thus low trust might reduce the enrollment rate. The net effect is likely to be a small and/or insignificant impact on enrollment decisions.

Village characteristics may influence individuals' pension enrollment decisions, for example, through peer learning and sharing of a village infrastructure to aid the enrollment process. The village may be particularly influential towards childless elders, those whose children have migrated, or who do not have close relations with their children.

Individuals aged 45-59 have incentives to enroll in NRPS, both for their own direct benefit and to help their older parents. While their own incentives are largely similar to the older cohort and interact with the enrollment decisions of their parents, there are additional considerations. Below we consider pension decisions from the perspective of the younger generation. We do not repeat the discussion about intergenerational links in the enrollment decision.

Just like the older generation, the younger generation should be more likely to enroll, the more years they can reap pension benefits relative to the number of years in which they will have to make payments. Thus, it is the individuals who are older but still under 60 who are more likely to enroll. They will have to contribute for fewer years before receiving benefits. They also bear a lower risk of losing benefits if the pension system falters. As explained before, having a pension-eligible spouse, having stronger trust in government or better decision-making abilities are all expected to promote pension enrollment, but financial protection may play a mixed role. A higher number of senior parents still alive, or not all children migrating out, are likely associated with greater enrollment. To the extent that the younger generation, especially migrants, has relatively weak ties to their home communities, the characteristics of the village might not significantly affect their enrollment decisions. Unlike the older parents who are required to have at least one child enroll in order to be eligible to enroll, the Family Binding Policy does not apply to the younger parents and their children. Therefore, the number of children in one's family only indicates the extent of informal old-age support that the younger parents receive; thus, more children in the family may dampen pension enrollment.

\subsection{Empirical Approach}

In our empirical analysis, we determine if the factors discussed above explain enrollment decisions as predicted from the above section. We analyze three enrollment outcomes, including the extensive margin (i.e. the decision to enroll) as well as intensive margins (i.e. the time to enrollment and premium paid). Specifically, we estimate the following:

$$
\text { Pension }_{i f v}=\alpha+X_{i}^{\prime} \beta+X_{f}^{\prime} \gamma+X_{v}^{\prime} \theta+\lambda_{c}+\varepsilon_{i f v}
$$

where Pension $_{i j v}$ is separately each one of the three outcome variables, and Xs are a 
rich set of covariates at the individual level ( $X_{i} ; i$ for individual), the family level ( $X_{f}$; $f$ for family), and the village level ( $X_{v} ; v$ for village). Information at all three levels is key to understanding enrollment decisions. The list of $X$ variables is summarized in section 4.2 and in Table 1. Also, because the NRPS was rolled out at the county level, all regressions account for county-specific heterogeneities by controlling for county fixed effects $\left(\lambda_{c}\right)$. Standard errors are clustered at the county level. All estimations are weighted to obtain nationally representative results. We present empirical findings separately for the older and younger cohorts, as explained above. In our sensitivity analysis, we test our results across three specifications. Then, using what we determine to be our preferred specification, we separately estimate female and male subsamples to capture gender differences.

\section{Data, Analytic Sample, and Variables}

\subsection{Data and Analytical Sample}

We use the China Family Panel Studies (CFPS) 2012 national sample to study determinants of the decision to enroll in NRPS, time to enrollment, and for individuals below age 60, premiums paid. The survey covers 44,693 individuals from 13,459 households across 25 provinces of China ${ }^{9}$, geographically representing $95 \%$ of the Chinese population (Xie and Lu 2015). Because the survey was fielded about two years after the rollout of NRPS, we can observe if, when, and to what extent an individual enrolled in NPRS ${ }^{10}$. The two-year gap allows substantial time for individuals to respond to the program.

Characteristics at the individual, family, and village levels hypothesized to affect enrollment decisions are available in the data set. For individuals, standard socioeconomic and demographic characteristics were collected, including education, family structure, age, income and wealth. Data were also obtained on health status, migration, county of residence, and a number of relatively rare variables pertinent to our study. The latter include the individual's trust in government and the functioning of the social security system. In addition, there is information on whether the individual is enrolled in any other public programs. The family level data have rich information on family composition, including adult children living away from home. For the older cohort, we match parents to their children even if they were not co-residing. For the younger cohort, we include both those with and without living parents. Phone surveys were used to contact migrant children. Such data are critical to our analysis of the intergenerational dynamics of pension enrollment. Data characterizing villages were also collected as part of the survey. Home villages can be important for enrollment decisions among the rural elderly.

Our analytical sample is restricted to individuals who are over age 45 and eligible for NRPS enrollment (i.e. holding rural registration). We analyze the sample by two age categories, i.e., individuals over age 60 who have children (4,635 observations) and

\footnotetext{
9 Hong Kong, Macao, Taiwan, Xinjiang, Qinghai, Inner Mongolia, Ningxia, and Hainan are excluded.

10 Because the NRPS rolled-out in most counties between 2010 and 2012, very few counties had initiated the program when the CFPS 2010 baseline sample was collected. Therefore, this current study uses only the CFPS 2012 sample.
} 
those aged 45-60 (6,811 observations, of whom 38.5 percent have no senior parents alive), to capture differing incentives to enroll and to contribute to the system. Except reporting the percentage that enrolls, we do not analyze the 142 childless older persons in our sample as the size is too small. We also ignore those under 45 as they have little incentive to enroll until later in life. Table 1 reports summary statistics for the two age cohorts.

\subsection{Variables}

Outcome measures. As indicated above, we examine three decisions related to enrollment in the NRPS: the decision to enroll, an individual's premium paid, and the decision time to enrollment. See Table 1 for summary statistics and Figure 1 for distributions by age. The decision to enroll is a binary variable, equal to 1 if an individual has enrolled and zero otherwise. The NRPS enrollment rate is, on average, 54.2 percent among the younger cohort and 59.5 percent among the older cohort. An individual's premium paid represents the level of individual contribution, ranging from zero to 7,200 CNY per year per person. The average pension premium, including those who do not enroll, is $89 \mathrm{CNY}$ per year per person among all people age 45-60, whether or not enrolled in the NRPS. The average pension premium among enrollees is 162 CNY per year per person. Decision time measures the years taken for an individual to enroll after the program became available at the county level. ${ }^{11}$ We calculated this from the date on which the program was initiated in their county until the date of their enrollment. We use the rollout dates for all counties listed in county-level official documents provided by China's Ministry of Human Resources and Social Security (Appendix Figure 3). Table 1 suggests that the younger cohort (aged 45-60) wait only slightly longer to make pension enrollment decisions compared to their older counterparts, which is consistent with the Family Binding Policy that requires older parents and their eligible children to enroll at the same time.

Control variables. Factors at the individual, family, and village level that may influence pension enrollment decisions are included in regressions. See Tables 2A and $2 \mathrm{~B}$ for the list of covariates for the older cohort and Tables $3 \mathrm{~A}-3 \mathrm{C}$ for that of the younger cohort. We control for somewhat different sets of variables due to the design of NRPS as discussed above.

Individual level variables. In both groups, we control for: age, gender, whether the individual is a household head, marital status, own and children's years of education, party membership, presence of chronic disease and impairment in activities of daily living (ADL), migration status (if outside the local county in the past year), enrollment in the New Cooperative Medical Scheme (NCMS) ${ }^{12}$, and enrollment in ORPS. For both groups, trust in government and concern over poor functioning of the social security system are respectively measured by three binary indicators, from low (responses of 0 $3)$, medium (4-6), to strong (7-10). The lowest category of each of these subjective

\footnotetext{
11 For those who did not enroll, their decision time is defined as the difference between the county level rollout date and the date of the interview. The results for premium paid and decision timing are not sensitive to exclusion of those who did not enroll by the survey date.

12 Since its rollout in 2003, NCMS has rapidly expanded its coverage, service use, cost control and quality. NCMS is now a cornerstone of China's rural health system (Meng and Xu 2014).
} 
assessments is omitted as the comparison group. For those aged 45-60, we also control for age groups 45-50 (omitted comparison group), 50-55 and 55-60 using binary indicators.

Family characteristics. For the older cohort, we control for household size, whether their spouses are age-eligible for pension benefits (no spouse as the comparison group), years of schooling of their most educated child, and the relationship with their children. For the younger cohort, we control for the existence of elderly parents, and then for those with at least one living elderly parent, parents' characteristics (e.g. age categories interacted with gender). We do not control for their relationship with parents as 38.5 percent of them have no parents alive. For both groups, we also control for: house value, land size, number of sons and daughters, whether all the children are outmigrants or not, and family income (excluding pension) in quintiles. See Appendix Table 1 for information on income quintiles; note that the bottom three quintiles were below the international poverty line at the time of the survey. ${ }^{13}$

Village characteristics. We also control for village factors, including income per capita, proportion of villagers enrolled, number of enrollees above the age of 60 who fail to claim benefits, and the elapsed time since the first villager received a pension payment. We also control for geographic access to health care and population size at the village level.

\section{Empirical Results}

In the regression tables for the older individuals, we examine their decision to enroll (Table 2A) and time to enrollment (Table 2B) in NRPS. However, because those over 60 are not required to contribute pension premiums, we cannot examine premiums paid. The full sample results across three specifications are displayed in columns (1) to (3). Specifically, we present column (1) with no measure of the relationship between parents and children, column (2) with such measures, and column (3) with an additional mechanistic factor - if any eligible child enrolls in the NRPS - as stipulated in the Family Binding Policy. Following our main specification in column (2), columns (4) and (5) separately estimate female and male subsamples because children's willingness to contribute financially and through in-person care might differ by gender of the parent.

In the regression tables for the younger individuals, we display the results for decision to enroll (Tables 3A), time to enrollment (Table 3B), and premiums paid (Table 3C). We present column (1) with number of living parents and their age profiles, column (2) adds if all children have migrated away from their parents, column (3) adds gender composition of living parents, and columns (4) and (5) separately estimating female and male subsamples using the same set of variables as column (2) for the full sample. We examine gender differences, as culturally sons play a larger role in ensuring the well-being of elders.

\section{Individuals 60 and above}

\footnotetext{
${ }^{13}$ Note also that pension benefits are not counted as income when assessing eligibility for social welfare programs, which rules out the potential concern that people in the lowest income quintile fail to enroll as they may become ineligible for other benefits due to their pension benefits.
} 
Our primary focus is on older persons who have children. However, as noted above, there are too few childless elders over 60 to analyze them, they are eliminated from our sample. We analyze only those with children. In general, relatively few personal characteristics affect both outcomes across the samples and specifications. Those who are younger among this set of those over 60 years old likely reap greater benefits to enrolling but are no more likely to enroll. Rather surprisingly, neither own education nor that of one's own children significantly promotes either enrollment decision among older persons. This lack of significance may occur as both the parents and children have very low levels of education; 2.17 and 4.92 respectively for the older and young cohort. Gender is never significant, but when estimates are conducted separately by gender there are a few differences in coefficients, particularly in time to enrollment. Specifically, coefficients on number of children in different age categories and the number of sons are significant for males but not for females in the time to enrollment. Contrary to expectations, the set of variables indicating the age categories of one's children are insignificant in both decisions. For example, elderly parents with children in their fifties are no more likely to enroll than others.

However, prior enrollment in other programs, i.e. health insurance (NCMS) and pension program (ORPS), are all significant. The results show that ORPS is a substitute (negative coefficients) for NRPS both in terms of enrollment and time to enrollment (positive coefficients). NCMS is a complement to NRPS in both decisions. These findings are consistent with the function of each of the programs. Compared to low trust, stronger trust in government increases enrollment and reduces time to enrollment. Having migrated out also significantly increases enrollment, but does not reduce time to enrollment. Note that only 1.1 percent of this older group have migrated.

We find scant evidence of within-couple coordination to maximize the gains for the family (only one time is one of the variables significant). For example, other things being equal, and compared to unmarried elderly persons, having a spouse above age 60 is not associated with a higher pension enrollment rate, as would be expected.

Out-migration of all children from the home county significantly reduces parental enrollment but only when controlling for if an eligible child has enrolled in the NRPS (column (3), Table 2A) and in the separate estimates for males (column (5) Table 2A). However, out-migration of all children is insignificant in all estimates of the time to enrollment. Parents who help their children to manage financial assets tend to enroll sooner in some specifications (column 2 Table 2A) and for women when estimated separately (column 4 Table 2A). This evidence weakly suggests that reduced intergenerational connectedness may discourage enrollment for some.

However, having a child enroll in NRPS is positively and significantly associated both with NRPS enrollment (column (3), Table 2A) and with a shorter time to enrollment (column 3, Table 2B). This is an expected mechanistic relationship, given the requirement for older persons to have at least one eligible child enrolled in the program if they are to receive benefits.

Only those in the lowest quintile of income are more likely to enroll and enroll more rapidly, while there are no significant impacts for the second and third quintiles of income. This means that a majority of poor older individuals are no more likely to 
take advantage of NRPS than their richer counterparts.

Village characteristics strongly influence individual pension enrollment decisions in ways that are consistent with the predicted signs. Specifically, individuals' enrollment rates are higher and enrollment is quicker if there are: 1) a larger share of villagers who enrolled in the NRPS; 2) a smaller number of enrollees above 60 in the village who failed to claim pension benefits; and 3) a villager who started to receive pension benefits at an earlier date. These village level findings are all consistent with peer learning, and perhaps with other factors, such as a strong village leader.

\section{Individuals aged 45-60}

Perhaps a more interesting and more complicated decision is that of children of elderly parents. Consistent with expectations, individuals are more likely to enroll when they are closer to the pension eligibility cut-off age. Specifically, age groups 50-55 and 55-60 are more likely to enroll, enroll with less delay, and pay higher premiums compared to the younger age group 45-50.

In this age group as compared to the older group, own education and that of the most educated child play a role in decisions. Specifically, own education increases premiums paid in all specifications but not for females. Children's education increases enrollment in all specifications but not for males, while children's education weakly promotes contributions to premiums in all specifications but not for females. There are other differences across the estimates by gender as well. For example, being a household head increases enrollment only in separate estimates for males.

Other individual level variables that are significantly and positively associated with at least one outcome measure are: male, years of schooling, household head, chronic diseases, ADL, and strong concern over the social security system. However, these are not consistently significant across the outcomes and specifications.

As we observe for the older cohort, enrolling in NCMS increases pension enrollment rates and reduces the time taken to enroll; however, it is insignificant in premiums paid. In addition, enrolling in ORPS reduces enrollment and premium contribution, and increases decision time. These results suggest that for this age group, ORPS is a substitute for NRPS and health insurance is a complement as is true for the older cohort. Strong trust in government has a similar, positive impact for this age group on enrollment and premiums paid and a negative impact on time to enrollment as similar to what was observed with the older cohort. ${ }^{14}$

As was found in the older cohort, there is little evidence of within-couple arrangements for the three NRPS enrollment outcomes. Only for the premium decision and only for when regressions are estimated separately by gender are any of the spouse variables significant. For women, having a spouse over age 60 has a negative impact on the premium, but for men having a spouse of any age increases premium contributions. In other words, wives promote husbands' enrollment, but not vice versa.

There is mixed evidence on the impact of intergenerational arrangements on

\footnotetext{
14 Our placebo tests replace trust in government by trust in parents, Americans, strangers or neighbors; but none of these is associated with pension enrollment decisions, suggesting that unobserved factors might not drive both trust and individual enrollment decisions. These results are available upon request.
} 
enrollment decisions among children aged 45-59 with parents age-eligible for NRPS. Some of the age categories measuring having two parents over age 60 are significant in the expected directions for the three enrollment decisions; with the omitted reference group of no senior parent. Specifically, having older parents (e.g. two parents 60-65 years old) increases both enrollment and premiums and reduces the time to enrollment. This is consistent with the idea that an increase in the number of eligible parents heightens the potential gains of NRPS participation for adult children. Having two parents over the age of 70 also increases enrollment and reduces time to enroll, but does not affect premiums. However, there is little such evidence when comparing only one parent over age 60. Further, parents with more sons significantly reduce pension premiums, but not in separate estimates for males.

The only significant impacts of income are for females in the second and the third lowest quintiles, indicating that females in two out of three low income groups are more likely to enroll. All of the other income variables have insignificant coefficients in the decision to enroll, the time to enrollment, and premiums paid.

It is interesting to note that village effects for this younger cohort are weaker than those for the older cohort. One plausible explanation is that peers may exert stronger influence on older persons compared to the younger generation, who are more educated and are more likely to migrate out; they may adjust their reference groups to those more relevant to their lives.

\section{Conclusions and Discussion}

We find evidence of low and suboptimal pension enrollment in NRPS by eligible individuals and their families. For the older cohort, few individual and family characteristics are significant in enrollment decisions, but village characteristics play an important role. For the younger cohort, we find that more individual-level characteristics are significant, including own and children's education. Village characteristics are important but not as much as for the older cohort. For both cohorts, we find little evidence that families make simple and mutually beneficial intra-family enrollment decisions. Our finding of suboptimal enrollment highlights the need for research to determine how best to improve enrollment.

The suboptimal enrollment takes several forms across different populations. Specifically, individuals enrolled in the unsubsidized ORPS could benefit by simply switching to the highly subsidized NRPS program, yet not all do. All childless elderly could enroll in NRPS without any financial risk, yet not all do. There are also benefits to be shared across generations through intra-family transfers, yet these financial gains for the elderly have also been left untapped. Relatively younger senior parents or senior parents with children approaching pension-eligible age have more to gain than others, but such benefits are not often realized.

Thus, many of China's rural elderly lack the financial support they need in old age and this problem is likely to remain incompletely addressed due to suboptimal enrollment. The problems may worsen as factors driving financial insecurity likely exacerbate the problem over time. The number of adult children migrating to cities is increasing as is the life expectancy, leaving older parents without in-person support 
possibly for many years. To address these challenges, China implemented NRPS in every county in the country. Despite the broad eligibility of the program and the financial gains possible, we find evidence of low and suboptimal participation. And thus, the full gains will not accrue due to the low take-up rates. Many of those who could most benefit from NRPS do not enroll.

Why do people leave money on the table? Low monetary returns to pension enrollment is unlikely to be a viable explanation. This would be particularly unlikely for those without children, for whom it would be costless to receive benefits. It is also unlikely among people who are over 60 years old, because their pension payments would be several times higher than the premiums that would have to be paid by their children. The family unit would be better off with enrollment, and side payments could be redistributed. Also, the operational cost of claiming pension benefits is low in China due to the direct transfers of pension payments to individuals' banking accounts. This might help to explain why we find that migrants do not enroll at a lower rate.

Enrollment could remain low due to a lack of understanding about the program and inability to understand the potential gains to intra-family enrollment decisions and redistribution in reaction to the Family Binding Policy and then to respond. Both may occur due to low education or low financial literacy. Distrust in government could also discourage pension enrollment, and our evidence supports this to some extent. However, as discussed, older cohorts are guaranteed a financial gain, or at least no downside financial risk, so this should mitigate their concern about trust. Our evidence suggests aspects of the village may promote optimal decisions, at least for the older cohort. One could postulate that, gains in education might mitigate this problem, but only for the children of the younger cohort, did we find a significant, beneficial effect of education on enrollment decisions.

This study has notable strengths including being the first analysis to examine suboptimal pension enrollment in NRPS; and also, to explore plausible explanations including intra-family and intergenerational arrangements. Our ability to link data on the generations enables us to observe these family dynamics. Also by collecting and matching county administrative data on pension roll-out with individual's pension choices, we can measure the actual to the optimal pension enrollment decisions.

Despite the strengths, this study has some limitations as well. One limitation is that this is largely a descriptive study. Another limitation is that despite the richness of these data there are some unmeasured factors such as a direct measure of financial literacy. Also, although we have education of the children for both generations, we do not have information on education and some other personal characteristics for the parents of the children age 45-59. This is due to the fact that 38 percent of them do not have a living parent (See Table 1).

The insights from this paper may be applied to other developing countries. As in China, the percentage of the elderly population in many other developing countries is growing more rapidly than younger cohorts, many of the elderly are poor and undereducated, and children are migrating to cities. Family ties are often strong, but social protection systems are weak. Emerging evidence demonstrates the benefits of enrolling in social pension programs in developing countries, but enrollment rates are 
low (Pension Watch 2017). The low enrollment can limit the economic, health and social benefits of such social pension programs. 


\section{References}

Auerbach, P., Genoni, ME., and Pages, C. 2007. Social Security Coverage and the Labor Market in Developing Countries. IZA Discussion Paper No. 2979.

Barr, A., \& Packard, T. 2003. Preferences, constraints, and substitutes for coverage under Peru's pension system. Background Paper for Regional Study on Social Security Reform, Office of the Chief Economist, Latin America and Caribbean Regional Office, World Bank.

Beshears J, Choi, J., Laibson, D., Madrian, BC., Milkman, KL. 2015. The Effect of Providing Peer Information on Retirement Savings Decisions. Journal of Finance 70(3): 1161-1201.

Cai, F., Giles, J., O'Keefe, P., Wang, D. 2012. The elderly and old age support in rural China. World Bank Publications.

Chen, X. 2016. Social pensions could reshape informal old-age care and improve health. National Institutes of Health. https://obssr.od.nih.gov/social-pensions-could-reshape-informalold-age-care-and-improve-health/

Chen, X., K. Eggleston. A. Sun. 2016. The Impact of Social Pensions on Intergenerational Relationship: Comparative Evidence from China. Forthcoming in Journal of the Economics of Aging.

Cheng, LG., Liu, H., Zhang, Y., Z. Zhao. 2016. The Health Implications of Social Pensions: Evidence from China's New Rural Pension Scheme. In press. Journal of Comparative Economics.

Choi, J., D. Laibson, and B. Madrian. 2011. “\$100 Bills on the Sidewalk: Violations of NoArbitrage in 401(k) Accounts," The Review of Economics and Statistics 93(3): 748-763.

Clark, RL., Maki, JA., and MS. Morrill. 2014. "Can Simple Informational Nudges Increase Employee Participation in a 401(k) Plan?” Southern Economic Journal 80(3): 677-701.

Crabbe, C. A. (Ed.). 2005. A quarter century of pension reform in Latin America and the Caribbean: lessons learned and next steps. IDB. https://publications.iadb.org/handle/11319/314

Ebenstein, A., and Leung, S. 2010. Son preference and access to social insurance: evidence from China's rural pension program. Population and Development Review, 36(1), 47-70.

Ho, K., J. Hogan, and FS. Morton. 2017. The impact of consumer inattention on insurer Pricing in the Medicare Part D Program. NBER Working Paper No. 21028.

Holzmann, R., Packard, T., and Cuesta, J. 2000. Extending coverage in multi-pillar pension systems: Constraints and hypotheses, preliminary evidence and future research agenda. World Bank Social Protection Discussion Paper, 2.

Hu, H. and Q. Qi, et al. 2012. "Analysis of hospital technical efficiency in China: Effect of 
health insurance reform." China Economic Review 23(4): 865-877.

Kimberly, S. B. and M. Grant, et al. 2010. "New evidence on the impact of China's New Rural Cooperative Medical Scheme and its implications for rural primary healthcare: multivariate difference-in-difference analysis." BMJ 341.

Lei, X. and W. Lin 2009. "The New Cooperative Medical Scheme in rural China: does more coverage mean more service and better health?" Health Economics 18(S2): S25-S46.

Lei, X., C. Zhang and Y. Zhao 2013. "Incentive problems in China's new rural pension program." Research in Labor Economics 37: 181-201.

Li, C. A., \& Olivera, J. 2005. Participation in the Peruvian reformed pension system. Economics Discussion Papers, 592.

Madrian, B. and D. Shea, 2001. "The Power of Suggestion: Inertia in 401(k) Participation and Savings Behavior," Quarterly Journal of Economics 116: 1149-1187.

Meng, Q. and K. Xu, 2014. Progress and challenges of the rural cooperative medical scheme in China. Bulletin of the World Health Organization 92: 447-451.

Packard, T., Shinkai, N., and Fuentes, R. 2002. The reach of social security in Latin America and the Caribbean. Background Paper for Regional Study on Social Security Reform, 30491. United Nations, Department of Economic and Social Affairs, Population Division 2013. World Population Ageing 2013. ST/ESA/SER.A/348.

Pension Watch. 2017. Social pensions database: Notes. Retrieved from HelpAge International. http://www.pension-watch.net/pensions/contact-us/social-pensions-database-notes/

Thaler, R. and CR. Sunstein. 2009. Nudge: Improving Decisions About Health, Wealth, and Happiness. Publisher: Penguin Books; Revised \& Expanded edition.

Thaler, R. 2016. Misbehaving: The Making of Behavioral Economics. Publisher: W. W. Norton \& Company.

United Nations, Department of Economic and Social Affairs, Population Division 2013. World Population Prospects: The 2012 Revision, DVD Edition.

Wagstaff, A. and M. Lindelow, et al. 2009. "Extending health insurance to the rural population: An impact evaluation of China's new cooperative medical scheme." Journal of Health Economics 28(1): 1-19.

Wang, XM, JB. Williamson, and M. Cansoy. 2016. "Developing Countries and Systemic Pension Reforms: Reflections on Some Emerging Problems." International Social Security 
Review 69(2): 85-106.

Williamson, JB, Esteban C., and LQ. Fang. 2017. "Rural Pension Reform in China: A Critical Analysis." Journal of Aging Studies 41: 67-74.

Xie, Y. and Lu, P. 2015. "The Sampling Design of the China Family Panel Studies (CFPS)." Chinese Journal of Sociology. 1(4): 471-484. 
Figure 1 NRPS Enrollment Decisions
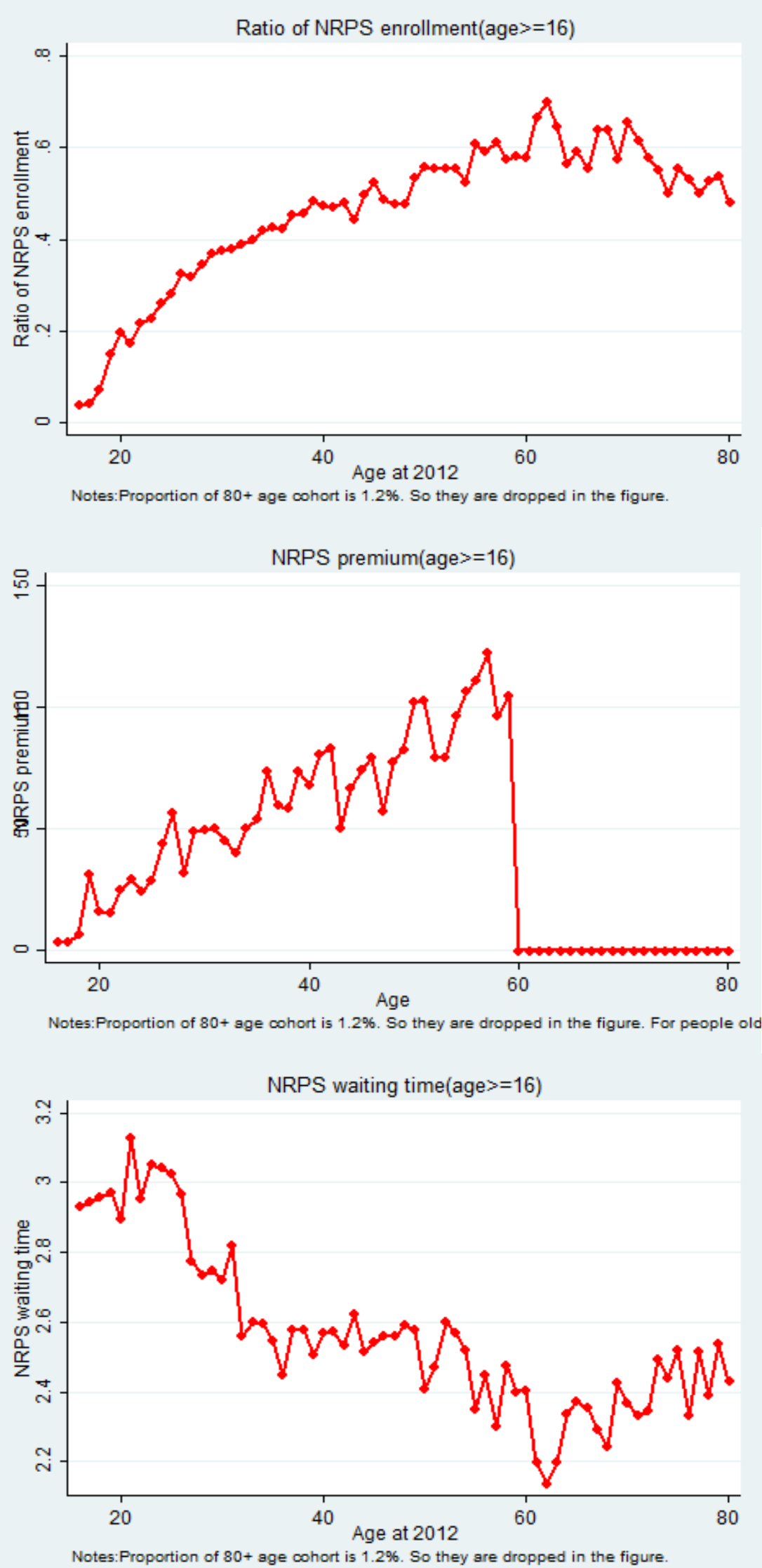

Note: All individuals with zero premium contributions are counted in when generating the average premium by age. 
Table 1 Summary Statistics

\begin{tabular}{|c|c|c|c|c|c|c|c|c|c|c|}
\hline & \multicolumn{5}{|c|}{ age $>=45 \&$ age $<60$} & \multicolumn{5}{|c|}{$\operatorname{age}>=60$} \\
\hline & $\mathrm{N}$ & mean & sd & $\min$ & $\max$ & $\mathrm{N}$ & mean & $\mathrm{sd}$ & $\min$ & $\max$ \\
\hline Whether enroll in NRPS (yes $=1$, no $=0$ ) & 6,811 & 0.542 & 0.498 & 0 & 1 & 4,635 & 0.595 & 0.491 & 0 & 1 \\
\hline Level of NRPS (CNY) & 6,467 & 89.110 & 259.932 & 0 & 7,200 & & & & & \\
\hline \multirow[t]{2}{*}{ Waiting time of NRPS (years) } & 6,148 & 2.493 & 1.381 & 0 & 5 & 4,067 & 2.330 & 1.393 & 0 & 5 \\
\hline & \multicolumn{10}{|c|}{ Individual Characteristics } \\
\hline Age is $[45,50)($ yes $=1, \mathrm{no}=0)$ & 6,811 & 0.412 & 0.492 & 0 & 1 & 4,635 & 0 & 0 & 0 & 0 \\
\hline Age is $[50,55)($ yes $=1, \mathrm{no}=0)$ & 6,811 & 0.255 & 0.436 & 0 & 1 & 4,635 & 0 & 0 & 0 & 0 \\
\hline Age is $[55,60)(\mathrm{yes}=1, \mathrm{no}=0)$ & 6,811 & 0.333 & 0.471 & 0 & 1 & 4,635 & 0 & 0 & 0 & 0 \\
\hline Age is $[60),($ yes $=1, \mathrm{no}=0)$ & 6,811 & 0 & 0 & 0 & 0 & 4,635 & 1 & 0 & 1 & 1 \\
\hline Age (year) & 6,811 & 51.598 & 4.527 & 45 & 59 & 4,635 & 67.993 & 6.739 & 60 & 99 \\
\hline Male $($ male $=1$, female $=0)$ & 6,811 & 0.478 & 0.500 & 0 & 1 & 4,635 & 0.479 & 0.500 & 0 & 1 \\
\hline Years of schooling in 2012 & 6,811 & 4.924 & 4.469 & 0 & 16 & 4,631 & 2.168 & 3.394 & 0 & 16 \\
\hline Household head $($ yes $=1$, no $=0)$ & 6,811 & 0.484 & 0.500 & 0 & 1 & 4,635 & 0.408 & 0.492 & 0 & 1 \\
\hline Marital status (married $=1$, single $=0$ ) & 6,811 & 0.944 & 0.229 & 0 & 1 & 4,634 & 0.773 & 0.419 & 0 & 1 \\
\hline Chronic disease $($ yes $=1, \mathrm{no}=0)$ & 6,811 & 0.136 & 0.343 & 0 & 1 & 4,630 & 0.195 & 0.396 & 0 & 1 \\
\hline Activities of Daily Living (ADL) impairment $($ yes $=1$, no $=0)$ & 6,808 & 0.063 & 0.242 & 0 & 1 & 4,624 & 0.200 & 0.400 & 0 & 1 \\
\hline Party membership $($ yes $=1$, no $=0)$ & 6,810 & 0.045 & 0.208 & 0 & 1 & 4,634 & 0.074 & 0.262 & 0 & 1 \\
\hline Low trust in government (yes $=1$, no $=0$ ) & 6,757 & 0.253 & 0.435 & 0 & 1 & 4,489 & 0.191 & 0.393 & 0 & 1 \\
\hline Medium trust in government $($ yes $=1$, no $=0$ ) & 6,757 & 0.484 & 0.500 & 0 & 1 & 4,489 & 0.472 & 0.499 & 0 & 1 \\
\hline Strong trust in government $(\mathrm{yes}=1, \mathrm{no}=0)$ & 6,757 & 0.263 & 0.440 & 0 & 1 & 4,489 & 0.337 & 0.473 & 0 & 1 \\
\hline Low concern re social security system $($ yes $=1, n o=0)$ & 6,811 & 0.287 & 0.453 & 0 & 1 & 4,635 & 0.324 & 0.468 & 0 & 1 \\
\hline Medium concern re social security system $($ yes $=1$, no $=0)$ & 6,811 & 0.391 & 0.488 & 0 & 1 & 4,635 & 0.356 & 0.479 & 0 & 1 \\
\hline Strong concern re social security system $($ yes $=1$, no $=0)$ & 6,811 & 0.270 & 0.444 & 0 & 1 & 4,635 & 0.213 & 0.410 & 0 & 1 \\
\hline Migrant $($ yes $=1, \mathrm{no}=0)$ & 6,791 & 0.054 & 0.226 & 0 & 1 & 4,629 & 0.011 & 0.103 & 0 & 1 \\
\hline NCMS health insurance enrollment (yes $=1, \mathrm{no}=0$ ) & 6,811 & 0.901 & 0.299 & 0 & 1 & 4,635 & 0.897 & 0.304 & 0 & 1 \\
\hline \multirow[t]{2}{*}{ ORPS pension enrollment $(\mathrm{yes}=1, \mathrm{no}=0)$} & 6,811 & 0.125 & 0.330 & 0 & 1 & 4,635 & 0.247 & 0.431 & 0 & 1 \\
\hline & \multicolumn{10}{|c|}{ Family Characteristics } \\
\hline No spouse $($ yes $=1 ;$ no $=0)$ & 6,811 & 0.056 & 0.229 & 0 & 1 & 4,635 & 0.227 & 0.419 & 0 & 1 \\
\hline Spouse is below 60 (yes $=1$, no or single or widow $=0)$ & 6,781 & 0.861 & 0.346 & 0 & 1 & 4,617 & 0.123 & 0.328 & 0 & 1 \\
\hline Spouse is above $60($ yes $=1$, no or single or widow $=0)$ & 6,781 & 0.083 & 0.277 & 0 & 1 & 4,617 & 0.650 & 0.477 & 0 & 1 \\
\hline 0 senior parent $(\mathrm{yes}=1, \mathrm{no}=0)$ & 6,315 & 0.385 & 0.487 & 0 & 1 & . & . & . & . & . \\
\hline 1 senior parent, ages $[60,65)($ yes $=1$, no $=0)$ & 6,315 & 0.003 & 0.058 & 0 & 1 & . & . & . & . & . \\
\hline 1 senior parent, ages $[65,70)($ yes $=1$, no $=0)$ & 6,315 & 0.022 & 0.147 & 0 & 1 & . & . & . & . & . \\
\hline
\end{tabular}


1 senior parent, ages $[70+)($ yes $=1, n 0=0)$

$2+$ senior parents, oldest ages $[60,65)(\mathrm{yes}=1, \mathrm{no}=0)$

$2+$ senior parents, oldest ages $[65,70)(\mathrm{yes}=1, \mathrm{no}=0)$

$2+$ senior parents, oldest ages $[70+)(\mathrm{yes}=1, \mathrm{no}=0)$

Whether children enroll in NRPS (yes $=1, \mathrm{no}=0$ )

Number of children age below 45

Number of children age $[45,50)$

Number of children age $[50,55)$

Number of children age $[55,60)$

Number of children age above 60

All child migrate? $($ yes $=1, n o=0)$

Highest years of education of their children

Household size

Number of sons

Number of daughters

House value $(10,000 \mathrm{CNY})$

Land size $(1,000 \mathrm{mu})$

Lowest quantile of income per capita (yes $=1, \mathrm{no}=0$ )

2 nd quantile of income per capita (yes $=1, \mathrm{no}=0)$

3 rd quantile of income per capita (yes $=1, n o=0$ )

4 th quantile of income per capita $(\mathrm{yes}=1, \mathrm{no}=0)$

Highest quantile of income per capita $(\mathrm{yes}=1, \mathrm{no}=0$ )

Economic help for children (yes $=1, \mathrm{no}=0$ )

Housework for children $($ yes $=1$, no $=0$ )

Take care of grandchildren (yes $=1, n o=0$ )

Financial management (yes $=1, \mathrm{no}=0$ )

Village income per capita $(1,000 \mathrm{CNY})$

$\%$ villagers enroll in NRPS

\# enrollees above age 60 fail to receive pension benefits

Population of the village

Time since the 1st villagers receives pension (year)

Time to nearest hospital (hour)

\begin{tabular}{|c|c|c|c|c|c|c|c|c|c|}
\hline 6,315 & 0.323 & 0.468 & 0 & 1 & . & . & . & . & . \\
\hline 6,315 & 0.002 & 0.044 & 0 & 1 & . & . & . & . & . \\
\hline 6,315 & 0.018 & 0.131 & 0 & 1 & . & . & . & . & . \\
\hline 6,315 & 0.247 & 0.431 & 0 & 1 & . & . & . & . & . \\
\hline . & . & . & . & . & 3,461 & 0.638 & 0.481 & 0 & 1 \\
\hline . & . & . & . & . & 4,635 & 2.164 & 1.226 & 0 & 7 \\
\hline . & . & . & . & . & 4,635 & 0.511 & 0.783 & 0 & 5 \\
\hline . & . & . & . & . & 4,635 & 0.190 & 0.492 & 0 & 3 \\
\hline . & . & . & . & . & 4,635 & 0.111 & 0.390 & 0 & 3 \\
\hline . & . & . & . & . & 4,635 & 0.044 & 0.273 & 0 & 4 \\
\hline 6,811 & 0.034 & 0.182 & 0 & 1 & 4,635 & 0.015 & 0.121 & 0 & 1 \\
\hline 6,800 & 10.840 & 3.805 & 0 & 22 & 4,633 & 9.457 & 3.684 & 0 & 22 \\
\hline 6,811 & 4.415 & 1.858 & 1 & 17 & 4,635 & 4.290 & 2.158 & 1 & 14 \\
\hline 6,811 & 1.143 & 0.731 & 0 & 5 & 4,635 & 1.671 & 1.002 & 0 & 6 \\
\hline 6,811 & 0.966 & 0.883 & 0 & 8 & 4,635 & 1.346 & 1.178 & 0 & 6 \\
\hline 6,792 & 14.156 & 33.343 & 0 & 2,000 & 4,604 & 14.183 & 51.359 & 0 & 2,000 \\
\hline 6,742 & 0.011 & 0.035 & 0 & 1 & 4,575 & 0.009 & 0.031 & 0 & 1 \\
\hline 6,811 & 0.200 & 0.400 & 0 & 1 & 4,635 & 0.201 & 0.401 & 0 & 1 \\
\hline 6,811 & 0.200 & 0.400 & 0 & 1 & 4,635 & 0.199 & 0.399 & 0 & 1 \\
\hline 6,811 & 0.200 & 0.400 & 0 & 1 & 4,635 & 0.200 & 0.400 & 0 & 1 \\
\hline 6,811 & 0.200 & 0.400 & 0 & 1 & 4,635 & 0.196 & 0.397 & 0 & 1 \\
\hline 6,811 & 0.200 & 0.400 & 0 & 1 & 4,635 & 0.205 & 0.403 & 0 & 1 \\
\hline . & . & . & . & . & 4,635 & 0.071 & 0.256 & 0 & 1 \\
\hline . & . & . & . & . & 4,635 & 0.265 & 0.441 & 0 & 1 \\
\hline . & . & . & . & . & 4,635 & 0.310 & 0.462 & 0 & 1 \\
\hline . & . & . & . & . & 4,635 & 0.017 & 0.128 & 0 & 1 \\
\hline \multicolumn{10}{|c|}{ Village Characteristics } \\
\hline 6,810 & 10.196 & 5.373 & 0 & 68 & 4,632 & 9.942 & 5.419 & -0 & 68 \\
\hline 6,809 & 0.471 & 0.280 & 0 & 1 & 4,634 & 0.470 & 0.281 & 0 & 1 \\
\hline 6,811 & 5.331 & 5.040 & 0 & 28 & 4,635 & 6.458 & 5.906 & 0 & 28 \\
\hline 6,811 & 2,192 & 1,850 & 31 & 23,000 & 4,635 & 2,215 & 1,784 & 16 & 23,300 \\
\hline 6,769 & 1.362 & 1.142 & 0 & 5 & 4,600 & 1.427 & 1.164 & 0 & 5 \\
\hline 6,784 & 0.198 & 0.271 & 0 & 5 & 4,598 & 0.233 & 0.304 & 0 & 5 \\
\hline
\end{tabular}


Table 2A Whether Enrolled (yes/no, for age $>=60$ )

\begin{tabular}{|c|c|c|c|c|c|c|c|c|c|c|}
\hline Dependent Variable: NRPS (yes/no) & \multicolumn{2}{|c|}{$\begin{array}{c}\text { (1) } \\
\text { All Sample }\end{array}$} & \multicolumn{2}{|c|}{$\begin{array}{c}\text { (2) } \\
\text { All Sample }\end{array}$} & \multicolumn{2}{|c|}{$\begin{array}{c}\text { (3) } \\
\text { All Sample }\end{array}$} & \multicolumn{2}{|c|}{$\begin{array}{c}(4) \\
\text { Female Sample }\end{array}$} & \multicolumn{2}{|c|}{$\begin{array}{c}\text { (5) } \\
\text { Male Sample }\end{array}$} \\
\hline \multicolumn{11}{|c|}{ Individual Characteristics } \\
\hline Age in 2012 & -0.002 & 0.002 & -0.002 & 0.002 & -0.002 & 0.002 & -0.001 & 0.002 & -0.002 & 0.003 \\
\hline Male & 0.019 & 0.017 & 0.022 & 0.017 & 0.020 & 0.016 & & & & \\
\hline Years of schooling in 2012 & -0.002 & 0.002 & -0.002 & 0.002 & -0.001 & 0.002 & -0.002 & 0.004 & -0.001 & 0.003 \\
\hline Household head & 0.004 & 0.015 & 0.002 & 0.015 & $0.024 *$ & 0.014 & 0.007 & 0.029 & 0.012 & 0.024 \\
\hline Chronic disease & -0.003 & 0.015 & -0.003 & 0.015 & -0.002 & 0.017 & -0.022 & 0.023 & 0.020 & 0.023 \\
\hline ADL impairments & -0.027 & 0.020 & -0.026 & 0.020 & -0.023 & 0.016 & -0.032 & 0.028 & -0.023 & 0.031 \\
\hline Party membership & -0.007 & 0.026 & -0.006 & 0.026 & -0.041 & 0.025 & 0.036 & 0.078 & -0.004 & 0.030 \\
\hline Medium trust in government & 0.003 & 0.019 & 0.005 & 0.018 & 0.011 & 0.018 & -0.010 & 0.024 & 0.011 & 0.022 \\
\hline Strong trust in government & $0.047 * *$ & 0.023 & $0.048 * *$ & 0.024 & $0.041 * *$ & 0.021 & 0.047 & 0.030 & 0.042 & 0.027 \\
\hline Medium severity of social security problem & $-0.039 * *$ & 0.015 & $-0.038 * *$ & 0.015 & -0.020 & 0.016 & $-0.043 *$ & 0.022 & -0.035 & 0.023 \\
\hline Strong severity of social security problem & -0.012 & 0.022 & -0.012 & 0.022 & -0.007 & 0.020 & -0.032 & 0.031 & 0.016 & 0.035 \\
\hline Migrant & $0.111^{* *}$ & 0.051 & $0.110 * *$ & 0.052 & 0.108 & 0.068 & $0.202 * *$ & 0.085 & $0.153 * * *$ & 0.051 \\
\hline NCMS health insurance enrollment & $0.176^{* * *}$ & 0.031 & $0.177 * * *$ & 0.031 & $0.140 * * *$ & 0.035 & $0.183 * * *$ & 0.036 & $0.182 * * *$ & 0.038 \\
\hline ORPS pension enrollment & $-0.326 * * *$ & 0.050 & $-0.331 * * *$ & 0.050 & $-0.279 * * *$ & 0.048 & $-0.291 * * *$ & 0.068 & $-0.372 * * *$ & 0.052 \\
\hline \multicolumn{11}{|c|}{ Family Characteristics } \\
\hline \multicolumn{11}{|c|}{ Within-couple arrangements/relationship (reference group=no spouse) } \\
\hline Whether spouse is below 60 & 0.032 & 0.026 & 0.035 & 0.027 & $0.064 * * *$ & 0.025 & -0.017 & 0.051 & 0.016 & 0.035 \\
\hline Whether spouse is above 60 & -0.006 & 0.020 & -0.005 & 0.020 & 0.012 & 0.018 & 0.013 & 0.025 & -0.030 & 0.029 \\
\hline \multicolumn{11}{|l|}{ Intergenerational arrangements/relationship } \\
\hline Number of children age below 45 & 0.151 & 0.150 & 0.150 & 0.151 & 0.110 & 0.112 & -0.014 & 0.083 & 0.165 & 0.199 \\
\hline Number of children age $[45,50)$ & 0.152 & 0.151 & 0.152 & 0.152 & 0.114 & 0.113 & -0.021 & 0.084 & 0.175 & 0.200 \\
\hline Number of children age $[50,55)$ & 0.138 & 0.154 & 0.139 & 0.155 & 0.117 & 0.114 & -0.026 & 0.091 & 0.169 & 0.202 \\
\hline Number of children age $[55,60)$ & 0.149 & 0.151 & 0.151 & 0.152 & 0.130 & 0.116 & 0.000 & 0.076 & 0.152 & 0.203 \\
\hline Number of children age above 60 & 0.135 & 0.154 & 0.137 & 0.156 & 0.080 & 0.115 & -0.034 & 0.101 & 0.169 & 0.205 \\
\hline Number of sons & -0.141 & 0.149 & -0.144 & 0.150 & -0.111 & 0.111 & 0.030 & 0.082 & -0.171 & 0.198 \\
\hline Whether all children are migrants? & & & -0.124 & 0.092 & $-0.160 * *$ & 0.081 & -0.032 & 0.100 & $-0.207^{*}$ & 0.107 \\
\hline Economic help for children & & & -0.011 & 0.029 & 0.023 & 0.036 & -0.033 & 0.055 & -0.014 & 0.037 \\
\hline Housework for children & & & 0.021 & 0.015 & 0.007 & 0.014 & 0.008 & 0.024 & 0.027 & 0.021 \\
\hline Take care of grandchildren & & & 0.014 & 0.014 & 0.005 & 0.014 & 0.017 & 0.021 & 0.014 & 0.023 \\
\hline
\end{tabular}


Financial management

$\begin{array}{cccc}0.012 & 0.065 & 0.019 & 0.063 \\ & & 0.357 * * * & 0.038\end{array}$

Whether children enroll in NRPS

Other Family Characteristics

Household size

House value

\begin{tabular}{cccccccccc}
0.001 & 0.002 & 0.001 & 0.002 & 0.003 & 0.002 & 0.002 & 0.003 & -0.001 & 0.003 \\
-0.001 & 0.004 & -0.002 & 0.004 & -0.004 & 0.004 & -0.003 & 0.005 & 0.000 & 0.005 \\
-0.000 & 0.000 & -0.000 & 0.000 & 0.000 & 0.000 & 0.000 & 0.000 & -0.000 & 0.000 \\
-0.025 & 0.177 & -0.038 & 0.172 & 0.036 & 0.260 & -0.031 & 0.158 & 0.125 & 0.426 \\
$0.135 * * *$ & 0.025 & $0.135 * * *$ & 0.025 & $0.075^{* * *}$ & 0.027 & $0.141^{* * *}$ & 0.036 & $0.137 * * *$ & 0.034 \\
-0.026 & 0.029 & -0.028 & 0.029 & -0.028 & 0.029 & -0.044 & 0.039 & -0.019 & 0.032 \\
-0.013 & 0.026 & -0.012 & 0.026 & -0.012 & 0.028 & -0.016 & 0.044 & -0.011 & 0.029 \\
0.011 & 0.030 & 0.012 & 0.030 & -0.010 & 0.027 & 0.033 & 0.040 & -0.003 & 0.033 \\
\hline
\end{tabular}

\section{Land size}

Lowest quintile of income per capita

2nd quintile of income per capita

3 rd quintile of income per capita

Village Characteristics

\begin{tabular}{|c|c|c|c|c|c|c|c|c|c|c|}
\hline & & & vinuge ch & acterts & & & & & & \\
\hline \multicolumn{11}{|l|}{ Fellow Villagers' Influences } \\
\hline$\%$ villagers enroll in NRPS & $0.617 * * *$ & 0.100 & $0.613 * * *$ & 0.099 & $0.254 * * *$ & 0.079 & $0.499 * * *$ & 0.116 & $0.764 * * *$ & 0.103 \\
\hline \# enrollees $>60$ fail to receive pension benefits & $-0.011 * * *$ & 0.003 & $-0.011 * * *$ & 0.003 & $-0.009 * * *$ & 0.002 & $-0.012 * * *$ & 0.004 & $-0.009 * * *$ & 0.003 \\
\hline \multirow{2}{*}{$\begin{array}{l}\text { Time since the } 1 \text { st villagers receives pension } \\
\text { Other Village Characteristics }\end{array}$} & $0.047 * * *$ & 0.012 & $0.045 * * *$ & 0.012 & $0.043 * * *$ & 0.013 & $0.052 * * *$ & 0.015 & $0.038 * * *$ & 0.013 \\
\hline & & & & & & & & & & \\
\hline Village income per capita & $0.003 *$ & 0.002 & $0.003 *$ & 0.002 & 0.001 & 0.001 & 0.001 & 0.002 & 0.004 & 0.003 \\
\hline Population of the village & -0.000 & 0.000 & -0.000 & 0.000 & 0.000 & 0.000 & -0.000 & 0.000 & $-0.000 * *$ & 0.000 \\
\hline Time to nearest hospital & $-0.049 *$ & 0.026 & $-0.048 *$ & 0.027 & -0.023 & 0.022 & $-0.038 *$ & 0.022 & -0.065 & 0.042 \\
\hline Number of observations & \multicolumn{2}{|c|}{4,331} & \multicolumn{2}{|c|}{4,331} & \multicolumn{2}{|c|}{3,243} & \multicolumn{2}{|c|}{2,205} & \multicolumn{2}{|c|}{2,126} \\
\hline Adjusted R2 & \multicolumn{2}{|c|}{0.545} & \multicolumn{2}{|c|}{0.546} & \multicolumn{2}{|c|}{0.636} & \multicolumn{2}{|c|}{0.551} & \multicolumn{2}{|c|}{0.559} \\
\hline
\end{tabular}

Notes: Standard errors are clustered at the county level. NRPS $=1$ if one enrolls in. All sample means combining the male and female samples. All income measures exclude pension benefits. Migration status is defined as being outside the local county in the past year. *10\% significance level. **5\% significance level. ***1\% significance level 
Table 2B Decision Time (year, for age $>=60$ )

\begin{tabular}{|c|c|c|c|c|c|c|c|c|c|c|}
\hline Dependent Variable: Decision time (year) & \multicolumn{2}{|c|}{$\begin{array}{c}\text { (1) } \\
\text { All Sample }\end{array}$} & \multicolumn{2}{|c|}{$\begin{array}{c}\text { (2) } \\
\text { All Sample }\end{array}$} & \multicolumn{2}{|c|}{$\begin{array}{c}\text { (3) } \\
\text { All Sample }\end{array}$} & \multicolumn{2}{|c|}{$\begin{array}{c}\text { (4) } \\
\text { Female Sample }\end{array}$} & \multicolumn{2}{|c|}{$\begin{array}{c}\text { (5) } \\
\text { Male Sample }\end{array}$} \\
\hline \multicolumn{11}{|c|}{ Individual Characteristics } \\
\hline Age in 2012 & -0.001 & 0.004 & -0.002 & 0.004 & -0.001 & 0.004 & -0.008 & 0.006 & 0.002 & 0.004 \\
\hline Male & -0.033 & 0.035 & -0.039 & 0.035 & -0.050 & 0.040 & & & & \\
\hline Years of schooling in 2012 & 0.003 & 0.005 & 0.004 & 0.005 & 0.003 & 0.006 & 0.004 & 0.008 & 0.005 & 0.006 \\
\hline Household head & -0.035 & 0.033 & -0.029 & 0.032 & -0.042 & 0.034 & -0.007 & 0.057 & -0.069 & 0.046 \\
\hline Chronic disease & -0.007 & 0.037 & -0.003 & 0.037 & -0.012 & 0.036 & -0.014 & 0.050 & -0.007 & 0.057 \\
\hline ADL impairments & 0.042 & 0.042 & 0.038 & 0.042 & $0.079 *$ & 0.041 & 0.069 & 0.060 & -0.006 & 0.084 \\
\hline Party membership & 0.016 & 0.060 & 0.017 & 0.059 & 0.067 & 0.068 & -0.188 & 0.137 & 0.063 & 0.064 \\
\hline Medium trust in government & -0.035 & 0.046 & -0.034 & 0.047 & -0.015 & 0.061 & -0.020 & 0.055 & -0.027 & 0.062 \\
\hline Strong trust in government & $-0.133 * *$ & 0.055 & $-0.133 * *$ & 0.056 & $-0.110^{*}$ & 0.064 & $-0.121 *$ & 0.066 & $-0.124^{*}$ & 0.068 \\
\hline Medium severity of social security problem & $0.084 * *$ & 0.040 & $0.085 * *$ & 0.040 & 0.047 & 0.044 & 0.067 & 0.057 & $0.093^{*}$ & 0.051 \\
\hline Strong severity of social security problem & -0.018 & 0.053 & -0.020 & 0.053 & -0.041 & 0.047 & -0.059 & 0.074 & -0.019 & 0.076 \\
\hline Migrant & -0.027 & 0.141 & -0.022 & 0.148 & -0.151 & 0.124 & -0.382 & 0.261 & -0.169 & 0.129 \\
\hline NCMS health insurance enrollment & $-0.284 * * *$ & 0.058 & $-0.286 * * *$ & 0.058 & $-0.243 * * *$ & 0.064 & $-0.186 * * *$ & 0.069 & $-0.402 * * *$ & 0.082 \\
\hline ORPS pension enrollment & $0.777 * * *$ & 0.109 & $0.795 * * *$ & 0.107 & $0.562 * * *$ & 0.111 & $0.760 * * *$ & 0.162 & $0.834 * * *$ & 0.100 \\
\hline \multicolumn{11}{|c|}{ Family Characteristics } \\
\hline \multicolumn{11}{|c|}{ Within-couple arrangements/relationship (reference group=no spouse) } \\
\hline Whether spouse is below 60 & -0.080 & 0.069 & -0.088 & 0.069 & -0.045 & 0.077 & -0.088 & 0.138 & -0.042 & 0.075 \\
\hline Whether spouse is above 60 & 0.059 & 0.046 & 0.060 & 0.046 & 0.052 & 0.044 & 0.038 & 0.068 & 0.076 & 0.051 \\
\hline \multicolumn{11}{|l|}{ Intergenerational arrangements/relationship } \\
\hline Number of children age below 45 & -0.223 & 0.291 & -0.234 & 0.286 & -0.033 & 0.360 & -0.126 & 0.278 & $-0.446^{*}$ & 0.233 \\
\hline Number of children age $[45,50)$ & -0.241 & 0.292 & -0.257 & 0.287 & -0.048 & 0.357 & -0.093 & 0.280 & $-0.519 * *$ & 0.238 \\
\hline Number of children age $[50,55)$ & -0.180 & 0.288 & -0.190 & 0.283 & -0.033 & 0.359 & -0.063 & 0.287 & $-0.454 * *$ & 0.222 \\
\hline Number of children age $[55,60)$ & -0.200 & 0.292 & -0.210 & 0.287 & -0.066 & 0.361 & -0.093 & 0.273 & $-0.446^{*}$ & 0.240 \\
\hline Number of children age above 60 & -0.216 & 0.298 & -0.235 & 0.294 & 0.017 & 0.364 & -0.086 & 0.297 & $-0.503 * *$ & 0.250 \\
\hline Number of sons & 0.217 & 0.291 & 0.232 & 0.286 & 0.035 & 0.360 & 0.087 & 0.275 & $0.488 * *$ & 0.231 \\
\hline Whether all children are migrants? & & & 0.142 & 0.159 & 0.145 & 0.180 & -0.026 & 0.155 & 0.285 & 0.190 \\
\hline Economic help for children & & & 0.025 & 0.062 & -0.043 & 0.070 & -0.008 & 0.086 & 0.005 & 0.082 \\
\hline Housework for children & & & -0.012 & 0.046 & 0.021 & 0.053 & 0.016 & 0.063 & -0.048 & 0.061 \\
\hline Take care of grandchildren & & & $-0.070 *$ & 0.038 & -0.067 & 0.044 & -0.073 & 0.047 & -0.076 & 0.054 \\
\hline Financial management & & & $-0.275 * *$ & 0.114 & -0.134 & 0.122 & $-0.465 * *$ & 0.214 & -0.201 & 0.174 \\
\hline Whether children enroll in NRPS & & & & & $-0.496 * * *$ & 0.067 & & & & \\
\hline
\end{tabular}




\begin{tabular}{|c|c|c|c|c|c|c|c|c|c|c|}
\hline Highest years of education of their children & -0.005 & 0.005 & -0.006 & 0.005 & -0.009 & 0.007 & -0.009 & 0.006 & -0.003 & 0.007 \\
\hline Household size & -0.001 & 0.008 & 0.004 & 0.009 & -0.001 & 0.010 & 0.005 & 0.011 & -0.002 & 0.012 \\
\hline House value & -0.000 & 0.000 & -0.000 & 0.000 & $-0.001 *$ & 0.000 & -0.000 & 0.000 & -0.000 & 0.000 \\
\hline Land size & -0.007 & 0.191 & -0.034 & 0.194 & 0.018 & 0.425 & 0.193 & 0.206 & -0.556 & 0.555 \\
\hline Lowest quintile of income per capita & $-0.262 * * *$ & 0.058 & $-0.264 * * *$ & 0.059 & $-0.148 * * *$ & 0.053 & $-0.282 * * *$ & 0.087 & $-0.247 * * *$ & 0.068 \\
\hline 2nd quintile of income per capita & 0.045 & 0.048 & 0.047 & 0.049 & 0.015 & 0.056 & 0.040 & 0.063 & 0.066 & 0.062 \\
\hline 3rd quintile of income per capita & -0.006 & 0.051 & -0.012 & 0.050 & -0.021 & 0.053 & -0.008 & 0.080 & -0.003 & 0.058 \\
\hline 4th quintile of income per capita & $-0.101 *$ & 0.057 & $-0.103 *$ & 0.055 & $-0.113 *$ & 0.066 & $-0.164 * *$ & 0.066 & -0.055 & 0.084 \\
\hline \multicolumn{11}{|c|}{ Village Characteristics } \\
\hline \multicolumn{11}{|l|}{ Fellow Villagers' Influences } \\
\hline$\%$ villagers enroll in NRPS & $-0.839 * * *$ & 0.282 & $-0.835 * * *$ & 0.282 & -0.215 & 0.287 & $-0.753 * *$ & 0.301 & $-1.047 * * *$ & 0.329 \\
\hline \# enrollees $>60$ fail to receive pension benefits & $0.021 * * *$ & 0.008 & $0.021 * * *$ & 0.008 & $0.017 * *$ & 0.007 & $0.021 *$ & 0.011 & $0.020 * * *$ & 0.007 \\
\hline Time since the 1 st villagers receives pension & $-0.214 * * *$ & 0.041 & $-0.212 * * *$ & 0.042 & $-0.261 * * *$ & 0.047 & $-0.240 * * *$ & 0.053 & $-0.157 * * *$ & 0.046 \\
\hline \multicolumn{11}{|l|}{ Other Village Characteristics } \\
\hline Village income per capita & $-0.008 *$ & 0.005 & $-0.008 *$ & 0.005 & -0.006 & 0.004 & -0.006 & 0.006 & -0.010 & 0.007 \\
\hline Population of the village & -0.000 & 0.000 & -0.000 & 0.000 & -0.000 & 0.000 & -0.000 & 0.000 & 0.000 & 0.000 \\
\hline Time to nearest hospital & $-0.081 *$ & 0.046 & -0.075 & 0.047 & $-0.125 * *$ & 0.052 & -0.058 & 0.067 & -0.022 & 0.069 \\
\hline Number of observations & \multicolumn{2}{|c|}{3,941} & \multicolumn{2}{|c|}{3,941} & \multicolumn{2}{|c|}{2,997} & \multicolumn{2}{|c|}{1,966} & \multicolumn{2}{|c|}{1,975} \\
\hline Adjusted R2 & \multicolumn{2}{|c|}{0.745} & \multicolumn{2}{|c|}{0.746} & \multicolumn{2}{|c|}{0.775} & \multicolumn{2}{|c|}{0.754} & \multicolumn{2}{|c|}{0.750} \\
\hline
\end{tabular}

Notes: NRPS decision time is defined as the time gap between enrollment date (or date of interview for non-participants) and county level rollout date. Other notes follow Table 2A. 
Table 3A Whether Enrolled (yes/no, for age $>=45$ \& age $<60$ )

\begin{tabular}{|c|c|c|c|c|c|c|c|c|c|c|}
\hline Dependent Variable: NRPS (yes/no) & \multicolumn{2}{|c|}{$\begin{array}{c}\text { (1) } \\
\text { All Sample }\end{array}$} & \multicolumn{2}{|c|}{$\begin{array}{c}\text { (2) } \\
\text { All Sample }\end{array}$} & \multicolumn{2}{|c|}{$\begin{array}{c}\text { (3) } \\
\text { All Sample }\end{array}$} & \multicolumn{2}{|c|}{$\begin{array}{c}\text { (4) } \\
\text { Female Sample }\end{array}$} & \multicolumn{2}{|c|}{$\begin{array}{c}\text { (5) } \\
\text { Male Sample }\end{array}$} \\
\hline \multicolumn{11}{|c|}{ Individual Characteristics } \\
\hline Age is $[50,55)$ & $0.068 * * *$ & 0.018 & $0.069 * * *$ & 0.018 & $0.069 * * *$ & 0.018 & $0.052 *$ & 0.027 & $0.090 * * *$ & 0.022 \\
\hline Age is $[55,60)$ & $0.097 * * *$ & 0.021 & $0.098 * * *$ & 0.021 & $0.099 * * *$ & 0.021 & $0.081 * * *$ & 0.025 & $0.122 * * *$ & 0.027 \\
\hline Male & -0.018 & 0.017 & -0.018 & 0.017 & -0.018 & 0.017 & & & & \\
\hline Years of schooling in 2012 & 0.003 & 0.002 & 0.003 & 0.002 & 0.003 & 0.002 & 0.002 & 0.003 & 0.003 & 0.002 \\
\hline Household head & 0.016 & 0.015 & 0.015 & 0.015 & 0.015 & 0.015 & -0.024 & 0.024 & $0.067 * * *$ & 0.025 \\
\hline Chronic disease & $0.046 * *$ & 0.021 & $0.046 * *$ & 0.021 & $0.045 * *$ & 0.020 & $0.058^{*}$ & 0.034 & $0.038 *$ & 0.022 \\
\hline ADL impairments & -0.044 & 0.033 & -0.045 & 0.033 & -0.045 & 0.033 & $-0.084 *$ & 0.047 & -0.003 & 0.035 \\
\hline Party membership & 0.052 & 0.033 & 0.052 & 0.033 & 0.052 & 0.033 & 0.050 & 0.039 & 0.098 & 0.072 \\
\hline Medium trust in government & 0.021 & 0.020 & 0.021 & 0.020 & 0.021 & 0.020 & 0.042 & 0.028 & 0.009 & 0.026 \\
\hline Strong trust in government & $0.051 * *$ & 0.023 & $0.052 * *$ & 0.023 & $0.051 * *$ & 0.023 & $0.070 * *$ & 0.031 & 0.036 & 0.027 \\
\hline Medium severity of social security problem & -0.006 & 0.016 & -0.006 & 0.016 & -0.005 & 0.016 & -0.002 & 0.023 & -0.014 & 0.025 \\
\hline Strong severity of social security problem & -0.031 & 0.019 & -0.031 & 0.019 & -0.030 & 0.019 & -0.014 & 0.023 & -0.043 & 0.030 \\
\hline Migrant & 0.020 & 0.026 & 0.019 & 0.026 & 0.020 & 0.026 & 0.021 & 0.030 & -0.006 & 0.062 \\
\hline NCMS health insurance enrollment & $0.245^{* * *}$ & 0.039 & $0.246^{* * *}$ & 0.039 & $0.246^{* * *}$ & 0.039 & $0.223 * * *$ & 0.046 & $0.268 * * *$ & 0.049 \\
\hline ORPS pension enrollment & $-0.386 * * *$ & 0.040 & $-0.387 * * *$ & 0.040 & $-0.386 * * *$ & 0.040 & $-0.364 * * *$ & 0.050 & $-0.404 * * *$ & 0.052 \\
\hline \multicolumn{11}{|c|}{ Family Characteristics } \\
\hline \multicolumn{11}{|c|}{ Within-couple arrangements/relationship (reference group=no spouse) } \\
\hline Whether spouse is below 60 & 0.003 & 0.027 & 0.002 & 0.026 & 0.002 & 0.026 & -0.019 & 0.033 & 0.041 & 0.042 \\
\hline Whether spouse is above 60 & 0.027 & 0.038 & 0.026 & 0.038 & 0.026 & 0.038 & 0.041 & 0.072 & 0.052 & 0.048 \\
\hline \multicolumn{11}{|c|}{ Intergenerational arrangements/relationship (reference group $=$ no senior parent) } \\
\hline 1 senior parent, ages $[60,65)$ & 0.032 & 0.097 & 0.028 & 0.095 & & & 0.134 & 0.106 & 0.033 & 0.141 \\
\hline 1 senior parent, ages $[65,70)$ & -0.033 & 0.046 & -0.034 & 0.046 & & & 0.022 & 0.087 & -0.063 & 0.067 \\
\hline 1 senior parent, ages $[70+)$ & 0.022 & 0.014 & 0.021 & 0.014 & & & $0.039 * *$ & 0.019 & 0.004 & 0.024 \\
\hline 1 senior parent, Male, ages $[60,65)$ & & & & & $0.328 * *$ & 0.147 & & & & \\
\hline 1 senior parent, Female, ages $[60,65)$ & & & & & -0.061 & 0.095 & & & & \\
\hline 1 senior parent, Male, ages $[65,70)$ & & & & & -0.076 & 0.105 & & & & \\
\hline 1 senior parent, Female, ages $[65,70)$ & & & & & -0.027 & 0.051 & & & & \\
\hline 1 senior parent, Male, ages $[70+)$ & & & & & $0.047 *$ & 0.025 & & & & \\
\hline 1 senior parent, Female, ages $[70+)$ & & & & & 0.013 & 0.015 & & & & \\
\hline
\end{tabular}


$2+$ senior parents, oldest ages $[60,65)$

$2+$ senior parents, oldest ages $[65,70)$

$\begin{array}{cc}0.170 * & 0.087 \\ 0.041 & 0.047 \\ 0.045^{* * *} & 0.015 \\ -0.010 & 0.014 \\ -0.012 & 0.009\end{array}$

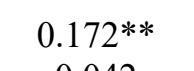

0.042

$0.045 * * * \quad 0.015$

$2+$ senior parents, oldest ages $[70+)$

Number of sons

Number of daughters

Whether all children are migrants?

Other Family Characteristics

Highest years of education of their children

$0.005^{* *} \quad 0.002$

Household size

House value

Land size

Lowest quintile of income per capita

2nd quintile of income per capita

3 rd quintile of income per capita

$-0.003$

0.002
0.004

$0.000 \quad 0.000$

$0.112 \quad 0.296$

$0.013 \quad 0.024$

$0.043 * \quad 0.024$

$0.062 * * \quad 0.025$

4 th quintile of income per capita

$0.019 \quad 0.026$

\section{Fellow Villagers' Influences \\ $\%$ villagers enroll in NRPS}

\# enrollees $>60$ fail to receive pension benefits

$0.987 * * * \quad 0.080$

$-0.007 * * * \quad 0.003$

$0.007 \quad 0.012$

Other Village Characteristics

Village income per capita

Population of the village

Time to nearest hospital

Number of observations

$-0.000 \quad 0.001$

$-0.000 \quad 0.000$

$0.001 \quad 0.036$

$-0.009 \quad 0.014$

$-0.011 \quad 0.009$
0.041

$0.041 \quad 0.046$

$\begin{array}{cc}0.171 * * & 0.086 \\ 0.043 & 0.047\end{array}$

$0.045^{* * *} \quad 0.015$

0.10

0.017

$-0.010 \quad 0.014$

$0.074 * * *$

$-0.011 \quad 0.010$

$-0.013$

0.046

0.019

$0.005 * * \quad 0.002$

$0.005 * * \quad 0.002$

$-0.003 \quad 0.004$

$0.000 \quad 0.000$

$0.007 * *$

$-0.003 \quad 0.004$

$\begin{array}{ll}0.000 & 0.000 \\ 0.116 & 0.298\end{array}$

$0.013 \quad 0.024$

$0.043 * \quad 0.024$

$0.062 * * \quad 0.025$

$\begin{array}{ll}0.118 & 0.299\end{array}$

$0.012 \quad 0.024$

$0.042 * \quad 0.024$

$0.061 * * \quad 0.025$

$0.019 \quad 0.026$

Village Characteristics

Adjusted R2

6,083

0.433

$\begin{array}{cc}0.987 * * * & 0.079 \\ -0.007 * * * & 0.002 \\ 0.007 & 0.012 \\ -0.000 & 0.001 \\ -0.000 & 0.000 \\ 0.001 & 0.036 \\ 6,083 & \\ 0.433 & \end{array}$

$0.985 * * * \quad 0.079$

$-0.007 * * * \quad 0.003$

$0.007 \quad 0.012$

$0.996 * * * \quad 0.087$

$-0.006^{* *} \quad 0.003$

$0.010 \quad 0.011$

$\begin{array}{cc}0.988 * * * & 0.104 \\ -0.008 * * & 0.004\end{array}$

$\begin{array}{llllll}-0.000 & 0.001 & -0.002 & 0.002 & 0.001 & 0.002\end{array}$

$-0.000 \quad 0.000$

$-0.000 \quad 0.000$

$\begin{array}{cc}0.001 & 0.002 \\ -0.000 & 0.000\end{array}$

$0.003 \quad 0.036$

0.054

0.037

$-0.039$

3,107

0.434

0.433

0.430

Notes: Follow Table 2. 
Table 3B Decision Time (year, for age $>=45 \&$ age $<60$ )

\begin{tabular}{|c|c|c|c|c|c|c|c|c|c|c|}
\hline Dependent Variable: Decision time (year) & \multicolumn{2}{|l|}{ (1) } & \multicolumn{2}{|l|}{ (2) } & \multicolumn{2}{|l|}{ (3) } & \multicolumn{2}{|l|}{ (4) } & \multicolumn{2}{|c|}{$\begin{array}{c}\text { (5) } \\
\text { Male Sample }\end{array}$} \\
\hline \multicolumn{11}{|c|}{ Individual Characteristics } \\
\hline Age is $[50,55)$ & $-0.075 *$ & 0.044 & $-0.075^{*}$ & 0.044 & $-0.076^{*}$ & 0.044 & -0.017 & 0.045 & $-0.123 *$ & 0.066 \\
\hline Age is $[55,60)$ & $-0.178 * * *$ & 0.044 & $-0.179 * * *$ & 0.044 & $-0.180 * * *$ & 0.044 & -0.088 & 0.055 & $-0.270 * * *$ & 0.065 \\
\hline Male & 0.035 & 0.036 & 0.035 & 0.036 & 0.035 & 0.036 & & & & \\
\hline Years of schooling in 2012 & -0.007 & 0.004 & -0.007 & 0.004 & -0.007 & 0.004 & -0.005 & 0.005 & -0.008 & 0.006 \\
\hline Household head & -0.025 & 0.029 & -0.025 & 0.029 & -0.024 & 0.029 & 0.045 & 0.052 & -0.084 & 0.055 \\
\hline Chronic disease & -0.056 & 0.045 & -0.056 & 0.045 & -0.057 & 0.045 & $-0.115^{*}$ & 0.066 & -0.041 & 0.056 \\
\hline ADL impairments & 0.065 & 0.053 & 0.065 & 0.053 & 0.067 & 0.053 & 0.145 & 0.089 & -0.015 & 0.059 \\
\hline Party membership & -0.028 & 0.058 & -0.028 & 0.059 & -0.028 & 0.059 & -0.006 & 0.071 & -0.162 & 0.172 \\
\hline Medium trust in government & $-0.069 *$ & 0.038 & $-0.068 *$ & 0.038 & $-0.069 *$ & 0.038 & $-0.112 * *$ & 0.050 & -0.045 & 0.050 \\
\hline Strong trust in government & $-0.088 *$ & 0.048 & $-0.088^{*}$ & 0.048 & $-0.087^{*}$ & 0.048 & $-0.155 * *$ & 0.061 & -0.031 & 0.060 \\
\hline Medium severity of social security problem & -0.036 & 0.036 & -0.037 & 0.036 & -0.038 & 0.036 & -0.033 & 0.052 & -0.031 & 0.051 \\
\hline Strong severity of social security problem & 0.046 & 0.035 & 0.046 & 0.035 & 0.045 & 0.035 & 0.053 & 0.047 & 0.039 & 0.062 \\
\hline Migrant & 0.012 & 0.052 & 0.012 & 0.052 & 0.011 & 0.052 & 0.051 & 0.067 & -0.019 & 0.133 \\
\hline NCMS health insurance enrollment & $-0.466 * * *$ & 0.081 & $-0.467 * * *$ & 0.081 & $-0.466 * * *$ & 0.081 & $-0.352 * * *$ & 0.089 & $-0.571 * * *$ & 0.121 \\
\hline ORPS pension enrollment & $0.676^{* * * *}$ & 0.115 & $0.676^{* * *}$ & 0.115 & $0.675 * * *$ & 0.115 & $0.541 * * *$ & 0.147 & $0.772 * * *$ & 0.132 \\
\hline \multicolumn{11}{|c|}{ Family Characteristics } \\
\hline \multicolumn{11}{|c|}{ Within-couple arrangements/relationship (reference group= no spouse) } \\
\hline Whether spouse is below 60 & 0.055 & 0.053 & 0.056 & 0.053 & 0.057 & 0.053 & 0.112 & 0.076 & -0.008 & 0.083 \\
\hline Whether spouse is above 60 & -0.037 & 0.083 & -0.037 & 0.083 & -0.036 & 0.083 & -0.022 & 0.150 & -0.064 & 0.105 \\
\hline \multicolumn{11}{|c|}{ Intergenerational arrangements/relationship (reference group=no senior parent) } \\
\hline 1 senior parent, ages $[60,65)$ & 0.212 & 0.144 & 0.218 & 0.147 & & & 0.165 & 0.213 & 0.125 & 0.259 \\
\hline 1 senior parent, ages $[65,70)$ & 0.036 & 0.108 & 0.036 & 0.108 & & & 0.008 & 0.143 & 0.057 & 0.186 \\
\hline 1 senior parent, ages $[70+)$ & -0.046 & 0.029 & -0.046 & 0.029 & & & $-0.088 * *$ & 0.043 & -0.003 & 0.047 \\
\hline 1 senior parent, Male, ages $[60,65)$ & & & & & $-0.338 * * *$ & 0.086 & & & & \\
\hline 1 senior parent, Female, ages $[60,65)$ & & & & & $0.280^{*}$ & 0.151 & & & & \\
\hline 1 senior parent, Male, ages $[65,70)$ & & & & & 0.036 & 0.226 & & & & \\
\hline 1 senior parent, Female, ages $[65,70)$ & & & & & 0.036 & 0.120 & & & & \\
\hline 1 senior parent, Male, ages $[70+)$ & & & & & $-0.083 *$ & 0.050 & & & & \\
\hline 1 senior parent, Female, ages $[70+)$ & & & & & -0.033 & 0.030 & & & & \\
\hline
\end{tabular}


$2+$ senior parents, oldest ages $[60,65)$

$2+$ senior parents, oldest ages $[65,70)$

$-0.463 * \quad 0.258$

$-0.189 *$

0.113

$-0.062 * \quad 0.037$

$2+$ senior parents, oldest ages $[70+$ )

$-0.008$

0.025

Number of daughters

$-0.008 \quad 0.018$

$-0.191^{*}$

0.258

$-0.009 \quad 0.025$

$-0.191 *$

$-0.062 *$

$-0.010$

$-0.008$

$-0.046$

0.019

$-0.010$

Whether all children are migrants?

Other Family Characteristics

Highest years of education of their children

$-0.004 \quad 0.005$

Household size

$0.002 \quad 0.009$

House value

Land size

Lowest quintile of inc per capita

$-0.000 \quad 0.000$

$-0.274 \quad 0.541$

$0.068 \quad 0.054$

2nd quintile of income per capita

3 rd quintile of income per capita

$0.042 \quad 0.044$

4 th quintile of income per capita

\section{Fellow Villagers' Influences \\ $\%$ villagers enroll in NRPS}

\# enrollees $>60$ fail to receive pension benefits

$-0.039$

0.061

$0.026 \quad 0.047$

\section{$-0.004 \quad 0.005$}

$-0.047$

\subsection{8}

0.113

0.037

0.025

0.019

0.072

$-0.225$

$-0.020$

0.108

$-0.079 \quad 0.056$

$-0.062 * * \quad 0.030$

$-0.038$

$\begin{array}{ll}-0.038 & 0.084\end{array}$

\section{$\begin{array}{ll}-0.005 & 0.007\end{array}$}

$0.003 \quad 0.009$

$\begin{array}{ll}-0.004 & 0.005\end{array}$

0.005
0.009

$-0.000$

$-0.279$

0.000

$-0.000$

$-0.284$

0.000

0.546

0.009

0.011

$0.000 \quad 0.001$

$0.046 \quad 0.496$

$0.039 \quad 0.075$

$0.042 \quad 0.044$

$0.069 \quad 0.054$

$0.043 \quad 0.044$

0.053

0.075
0.066

0.060

$-0.120$

0.078

$0.026 \quad 0.047$

Village Characteristics

Time since the 1 st villagers receives pension

Other Village Characteristics

Village income per capita

Population of the village

Time to nearest hospital

Number of observations

\begin{tabular}{cc}
$-1.354 * * *$ & 0.369 \\
0.006 & 0.007 \\
-0.005 & 0.059 \\
& \\
0.001 & 0.005 \\
0.000 & 0.000 \\
-0.080 & 0.076 \\
5,522 & \\
0.687 & \\
\hline
\end{tabular}

\section{$\begin{array}{cc}-1.354 * * * & 0.369 \\ 0.006 & 0.007\end{array}$}

$-1.353 * * * 20$

0.004

0.065

$\begin{array}{ll}-0.005 & 0.059\end{array}$

$-1.353 * * * \quad 0.369$

$0.001 \quad 0.005$

$\begin{array}{ll}0.001 & 0.005 \\ 0.000 & 0.000\end{array}$

0.006

0.007

$-1.199 * * *$

$1.199 * * * \quad 0.333$

$-0.080 \quad 0.078$

0.001

$0.000 \quad 0.000$

$\begin{array}{ll}-0.082 & 0.077\end{array}$

5,522

0.687

5,522

5,522
0.687

Notes: Follow Table 2. 
Table 3C Premium Paid (CNY, for age $>=45 \&$ age $<60$ )

\begin{tabular}{|c|c|c|c|c|c|c|c|c|c|c|}
\hline Dependent Variable: Premium (CNY) & \multicolumn{2}{|c|}{$\begin{array}{c}\text { (1) } \\
\text { All Sample }\end{array}$} & \multicolumn{2}{|c|}{$\begin{array}{c}(2) \\
\text { All Sample } \\
\end{array}$} & \multicolumn{2}{|c|}{$\begin{array}{c}\text { (3) } \\
\text { All Sample }\end{array}$} & \multicolumn{2}{|c|}{$\begin{array}{c}\text { (4) } \\
\text { Female Sample }\end{array}$} & \multicolumn{2}{|c|}{$\begin{array}{c}\text { (5) } \\
\text { Male Sample }\end{array}$} \\
\hline \multicolumn{11}{|c|}{ Individual Characteristics } \\
\hline Age is $[50,55)$ & $34.718 * * *$ & 11.740 & $34.329 * * *$ & 11.690 & $34.469 * * *$ & 11.728 & $37.959 * * *$ & 14.536 & $35.933 *$ & 19.288 \\
\hline Male & $-18.294 *$ & 10.974 & $-18.265^{*}$ & 10.981 & $-18.337^{*}$ & 10.994 & & & & \\
\hline Years of schooling in 2012 & $2.179 * *$ & 1.069 & $2.171 * *$ & 1.072 & $2.200 * *$ & 1.073 & 1.646 & 1.843 & $2.575^{*}$ & 1.556 \\
\hline Household head & 1.918 & 12.697 & 2.048 & 12.621 & 1.705 & 12.665 & -25.317 & 16.760 & $26.336^{*}$ & 15.283 \\
\hline Chronic disease & -4.273 & 8.525 & -4.451 & 8.619 & -4.731 & 8.671 & 6.478 & 20.263 & $-20.532 *$ & 11.976 \\
\hline ADL impairments & $-25.810 * *$ & 11.952 & $-25.240 * *$ & 11.782 & $-25.449 * *$ & 11.686 & $-42.665 * * *$ & 13.969 & -8.711 & 15.838 \\
\hline Party membership & -22.955 & 18.709 & -23.102 & 18.684 & -23.001 & 18.695 & -10.837 & 19.063 & -52.124 & 34.995 \\
\hline Medium trust in government & 8.845 & 12.890 & 8.847 & 12.849 & 8.957 & 12.855 & $24.988 * *$ & 12.034 & 0.245 & 26.766 \\
\hline Strong trust in government & $43.567 * *$ & 18.700 & $43.497 * *$ & 18.686 & $43.372 * *$ & 18.650 & $72.049 * *$ & 35.715 & $23.025 *$ & 12.645 \\
\hline Medium severity of social security problem & -12.485 & 11.438 & -12.574 & 11.450 & -12.378 & 11.454 & -17.282 & 11.369 & -13.237 & 19.668 \\
\hline Strong severity of social security problem & $-24.169 * *$ & 11.037 & $-24.228 * *$ & 11.033 & $-23.915 * *$ & 11.001 & -28.457 & 23.344 & -20.988 & 20.398 \\
\hline Migrant & -11.641 & 13.698 & -11.254 & 13.532 & -11.039 & 13.505 & -24.158 & 15.168 & -0.188 & 17.192 \\
\hline NCMS health insurance enrollment & 36.770 & 31.690 & 36.252 & 31.159 & 36.127 & 31.096 & -14.961 & 33.296 & 85.530 & 57.262 \\
\hline ORPS pension enrollment & $-72.662 * *$ & 33.255 & $-72.470 * *$ & 33.420 & $-71.957 * *$ & 33.538 & -47.347 & 54.781 & $-109.347 *$ & 59.010 \\
\hline \multicolumn{11}{|c|}{ Within-couple arrangements/relationship (reference group=no spouse) } \\
\hline Whether spouse is below 60 & 12.383 & 15.992 & 13.127 & 16.311 & 12.907 & 16.345 & -5.643 & 25.519 & $39.105 *$ & 19.989 \\
\hline Whether spouse is above 60 & 8.950 & 22.903 & 9.350 & 22.923 & 9.204 & 22.910 & $-57.190 *$ & 29.878 & $47.401 *$ & 26.672 \\
\hline \multicolumn{11}{|c|}{ Intergenerational arrangements/relationship (reference group=no senior parent) } \\
\hline 1 senior parent, ages $[60,65)$ & 2.330 & 35.523 & 5.431 & 35.362 & & & 7.987 & 32.058 & 33.018 & 51.973 \\
\hline 1 senior parent, ages $[65,70)$ & -24.207 & 18.385 & -23.493 & 17.365 & & & -15.768 & 43.626 & $-33.150 * *$ & 15.266 \\
\hline 1 senior parent, ages $[70+)$ & -9.115 & 13.817 & -8.968 & 13.739 & & & -11.340 & 21.642 & -4.197 & 14.886 \\
\hline 1 senior parent, Male, ages $[60,65)$ & & & & & $114.661 *$ & 62.156 & & & & \\
\hline 1 senior parent, Female, ages $[60,65)$ & & & & & -21.837 & 32.576 & & & & \\
\hline 1 senior parent, Male, ages $[65,70)$ & & & & & -36.598 & 28.533 & & & & \\
\hline 1 senior parent, Female, ages $[65,70)$ & & & & & -21.025 & 17.774 & & & & \\
\hline 1 senior parent, Male, ages $[70+)$ & & & & & 3.788 & 15.005 & & & & \\
\hline 1 senior parent, Female, ages $[70+)$ & & & & & -13.163 & 14.163 & & & & \\
\hline
\end{tabular}


$2+$ senior parents, oldest ages $[60,65)$

$2+$ senior parents, oldest ages $[65,70)$

$2+$ senior parents, oldest ages $[70+)$

Number of sons

Number of daughters

Whether all children are migrants?

Other Family Characteristics

Highest years of education of their children

Household size

House value

Land size

Lowest quintile of inc per capita

2nd quintile of income per capita

3 rd quintile of income per capita

4th quintile of income per capita

$\begin{array}{cc}45.021 * & 25.286 \\ 2.126 & 17.995 \\ 10.405 & 8.019 \\ -22.197 * * & 9.985 \\ 4.297 & 3.949\end{array}$

$43.883 * \quad 25.888$

$1.012 \quad 18.261$

$10.505 \quad 8.023$

$-22.677 * * \quad 10.257$

$3.176-3.804$

$-27.985$

25.702

$2.351 * \quad 1.395$

$-1.379$

$-0.170$

31.128

$-4.369$

$-8.108$

$-5.094$

$-11.590$

\subsection{0}

$2.382 * \quad 1.371$

$-1.191 \quad 1.971$

$-0.177 \quad 0.220$

$28.493 \quad 46.794$

$-4.143 \quad 28.995$

29.091

24.702

23.481

$\begin{array}{ll}-7.873 & 24.599\end{array}$

$\begin{array}{ll}-5.314 & 23.657\end{array}$

$24.780 \quad-11.630 \quad 24.854$

Village Characteristics

\begin{tabular}{cccccc}
$43.749^{*}$ & 25.868 & 9.964 & 34.316 & 51.458 & 56.136 \\
1.136 & 18.283 & -8.537 & 15.260 & 8.591 & 24.834 \\
10.447 & 8.016 & 12.268 & 11.854 & 9.500 & 15.363 \\
$-22.926^{* *}$ & 10.319 & $-19.336^{* *}$ & 9.264 & -23.959 & 15.136 \\
3.110 & 3.777 & -2.772 & 4.296 & 10.287 & 7.112 \\
-27.359 & 25.828 & -24.599 & 30.266 & -27.489 & 26.886 \\
& & & & & \\
$2.359 *$ & 1.365 & 2.073 & 1.526 & $3.327 *$ & 1.972 \\
-1.082 & 1.970 & -1.855 & 2.931 & 0.526 & 2.570 \\
-0.178 & 0.221 & -0.621 & 0.404 & 0.022 & 0.309 \\
30.070 & 47.302 & 68.606 & 70.331 & -61.776 & 141.605 \\
-4.343 & 29.023 & 0.547 & 37.764 & -3.593 & 30.568 \\
-8.150 & 24.639 & -11.559 & 25.736 & -6.366 & 32.378 \\
-5.963 & 23.706 & -13.730 & 26.128 & 3.245 & 31.980 \\
-11.914 & 24.874 & -17.849 & 23.853 & -7.074 & 40.060 \\
\hline
\end{tabular}

\section{Fellow Villagers' Influences}

$\%$ villagers enroll in NRPS

\# enrollees $>60$ fail to receive pension benefits

Time since the 1st villagers receives pension

Other Village Characteristics

Village income per capita

Population of the village

Time to nearest hospital

$191.029 * * \quad 83.268$

$-0.888 \quad 1.974$

\section{$191.387 * * \quad 83.874$ \\ $-0.867$ \\ 1.981}

$191.021 * * 0.83 .950$

$26.721 * \quad 15.364$

$191.021 * * \quad 83.950$

$26.600 * \quad 15.218$

$-0.847$

1.983

$4.847 \quad 3.754$
-0.003

$\begin{array}{rr}4.830 & 3.751 \\ -0.003 & 0.004\end{array}$

27.743

0.004
17.784

$-0.003$

3.754
0.004

27.655

17.401

$\begin{array}{ll}5,790 & 5,790 \\ 0.105 & 0.105\end{array}$

$\begin{array}{ll}5,790 & 5,790 \\ 0.105 & 0.105\end{array}$

\section{$268.879 * *$}

12.287

15.627

4.861

$-0.003$

3.745

Number of observations

Number of o
Adjusted R2
0.004

5,790

0.105
$3.698 \quad 3.193$

$0.002 \quad 0.008$

$17.873 \quad 18.535$

2,836

0.109
$119.267 \quad 76.904$

$-1.992 \quad 3.050$

$40.348 * * \quad 20.322$

$6.538 \quad 4.577$

$-0.009 * \quad 0.005$

$36.577 \quad 24.364$

2,954

Notes: NRPS premium $=0$ is coded for non-participants. Other notes follow Table 2 


\section{Appendix}

\section{Appendix Figure 1 - Statistics on the Rural Pension System in China (2002-2014)}
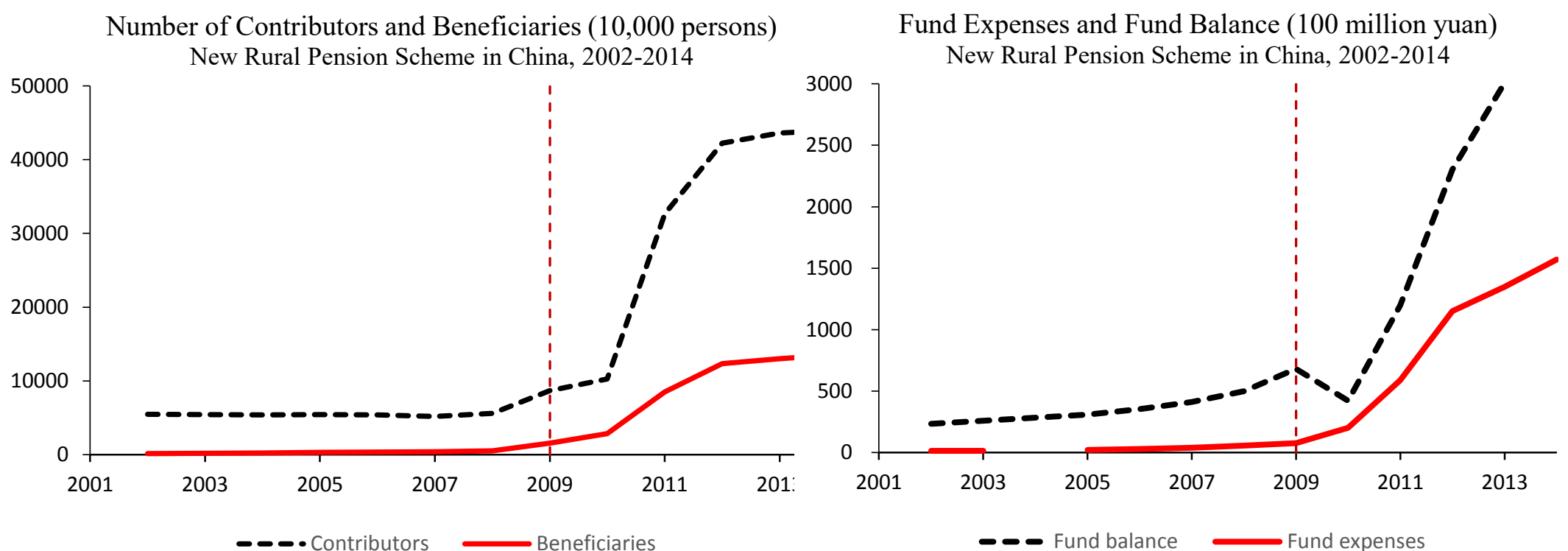

Source: China Labor Statistical Yearbooks (2004-2014), Statistical Bulletin on the Social Development of Human Resources and Social Security (2002-2014).

Notes: The NRPS initiated at the end of 2009. The non-zero figures before 2009 represent the unsubsidized ORPS that covered a tiny proportion of rural residents, mainly in developed regions in China. 


\section{Appendix Figure 2 - Pension Enrollment Rate by Age and Type of Pension}

\section{Enrollment Rate by Age and Types of Pension}

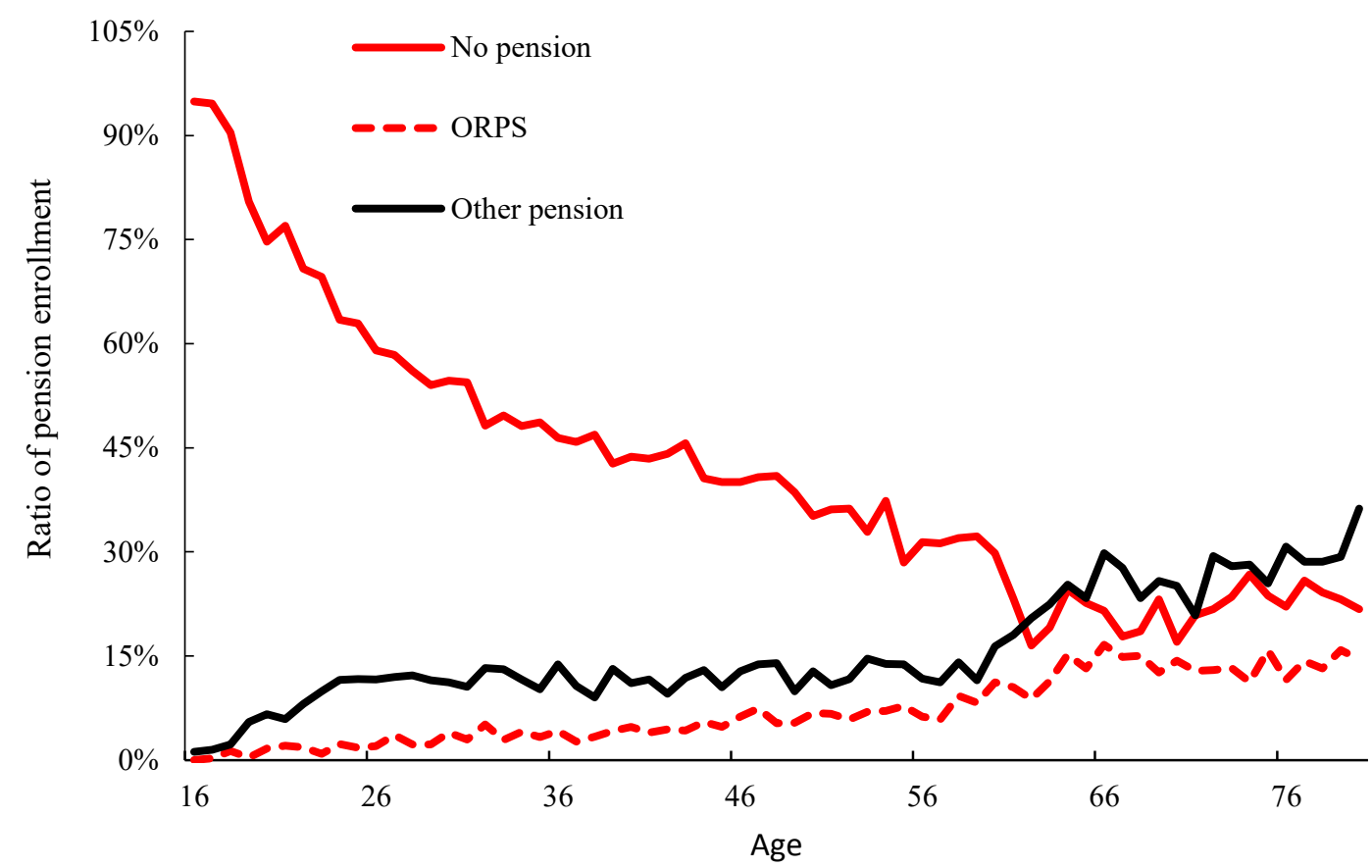

Notes: Proportion of $80+$ age cohort is $1.2 \%$. So they are dropped in the figure.

Notes: Only 1.2 percent of respondents are above age 80, and they are excluded from this figure. Other pensions mainly include commercial pension and pension subsidy to the oldest of old, and a tiny proportion of enterprise employee pension or government and public institution employee pension. Having commercial pensions or pension subsidy to the oldest of old does not preclude people from enrolling in NRPS. Note that there is no policy regarding potential reduced benefits if one enrolled in more than one of these programs. While the unsubsidized ORPS is still in operation (but not accepting new enrollment) and people are not allowed to enroll in NRPS and ORPS at the same time, rational agents should simply switch from this program to the highly subsidized NRPS with higher return and lower risk. 
Appendix Figure 3 - The Rollout of New Rural Pension Scheme in China

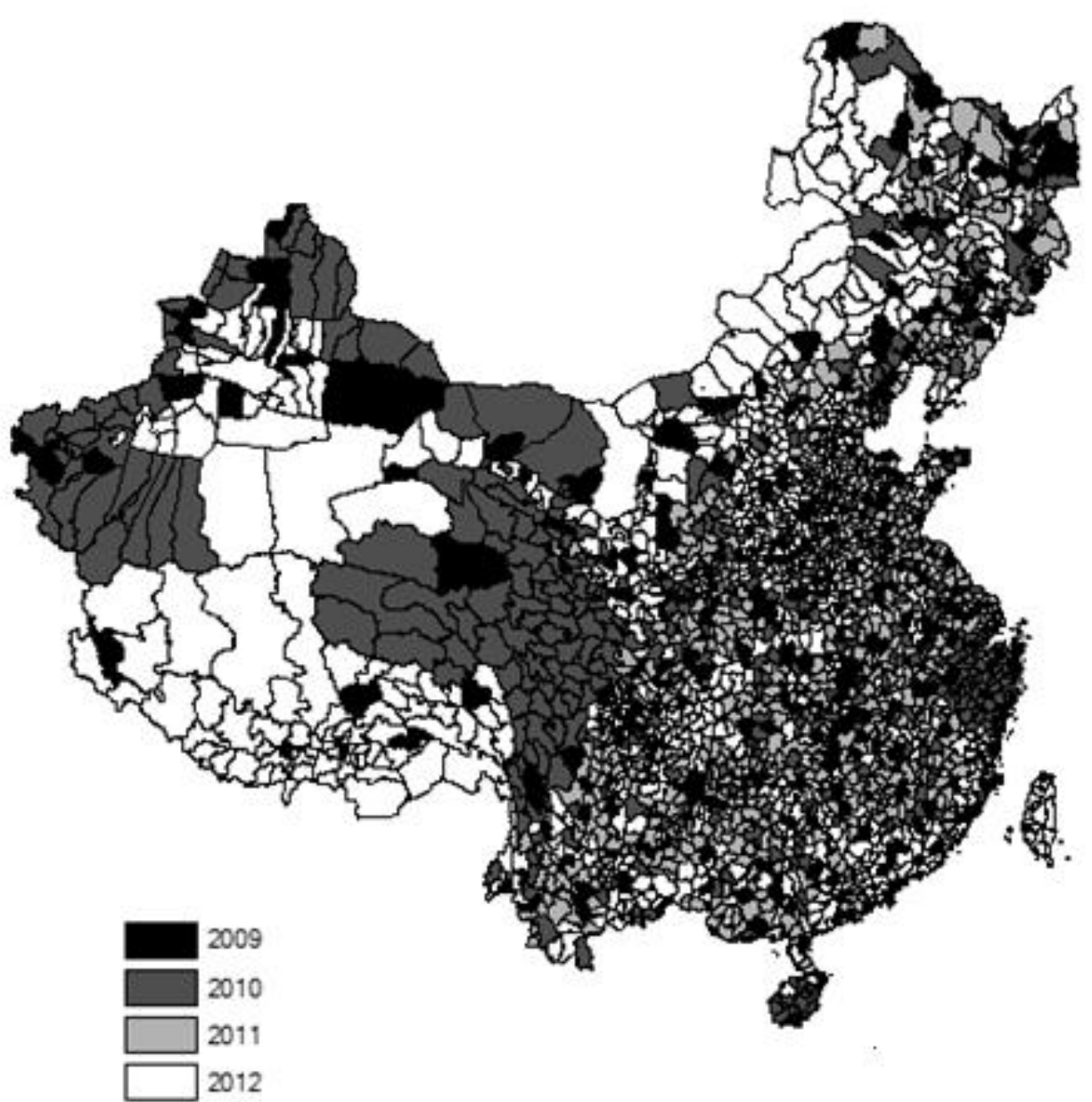

Notes: The NRPS was rolled out at the county level between 2009-2012. 
Appendix Table 1 - Summary Statistics of Income per capita by quintile (for those age $>45$ )

\begin{tabular}{lccccc}
\hline \hline & $\mathrm{N}$ & mean & $\mathrm{Sd}$ & $\min$ & $\max$ \\
\hline Income per capita (1000 CNY) & & & & & \\
Lowest quintile & 1,360 & 0.082 & 0.706 & -12.2 & 0.5 \\
2nd quintile & 1,361 & 1.004 & 0.314 & 0.5 & 1.6 \\
3rd quintile & 1,364 & 2.713 & 0.769 & 1.6 & 4.2 \\
4th quintile & 1,361 & 7.343 & 2.246 & 4.2 & 12.0 \\
Highest quintile & 1,357 & 29.552 & 30.507 & 12.0 & 500.0 \\
\hline \hline
\end{tabular}

Data: CFPS (2012)

Notes: The 1.90 USD international poverty line corresponds to $4,577 \mathrm{CNY}$ per person per year (1 USD $=6.60 \mathrm{CNY}$ ).

Therefore, all individuals in the lowest three income quintiles were below the international poverty line at the time of survey. 